IZA DP No. 9256

Wage Risk and the Value of Job Mobility in Early Employment Careers

Kai Liu

August 2015 


\title{
Wage Risk and the Value of Job Mobility in Early Employment Careers
}

\author{
Kai Liu \\ Norwegian School of Economics \\ and IZA
}

Discussion Paper No. 9256

August 2015

IZA

P.O. Box 7240

53072 Bonn

Germany

Phone: +49-228-3894-0

Fax: +49-228-3894-180

E-mail: iza@iza.org

Any opinions expressed here are those of the author(s) and not those of IZA. Research published in this series may include views on policy, but the institute itself takes no institutional policy positions. The IZA research network is committed to the IZA Guiding Principles of Research Integrity.

The Institute for the Study of Labor (IZA) in Bonn is a local and virtual international research center and a place of communication between science, politics and business. IZA is an independent nonprofit organization supported by Deutsche Post Foundation. The center is associated with the University of Bonn and offers a stimulating research environment through its international network, workshops and conferences, data service, project support, research visits and doctoral program. IZA engages in (i) original and internationally competitive research in all fields of labor economics, (ii) development of policy concepts, and (iii) dissemination of research results and concepts to the interested public.

IZA Discussion Papers often represent preliminary work and are circulated to encourage discussion. Citation of such a paper should account for its provisional character. A revised version may be available directly from the author. 


\section{ABSTRACT}

\section{Wage Risk and the Value of Job Mobility in Early Employment Careers*}

This paper shows that job mobility is a valuable channel which employed workers use to mitigate bad labor market shocks. I construct and estimate a model of wage dynamics jointly with a dynamic model of job mobility. The key feature of the model is the specification of wage shocks at the worker- firm match level, for workers can respond to these shocks by changing jobs. The model is estimated using a sample of young male workers from the 1996 panel of Survey of Income and Program Participation. The first result is that the variance of match-level shocks is large, and the consequent value of job mobility is substantial. The second result is that true wage risk is almost three times as large as the wage variance observed after job mobility, which is what other papers in the literature have called wage risk. This suggests a very different picture of the risks facing employed workers in the labor market.

JEL Classification: D91, J31, J62

Keywords: job mobility, wage dynamics, wage risk, employment

Corresponding author:

Kai Liu

Department of Economics

Norwegian School of Economics

Helleveien 30

NO-5045 Bergen

Norway

E-mail: kai.liu@nhh.no

\footnotetext{
* This is a revised version of the first chapter of my dissertation at Johns Hopkins University. I am grateful to Robert Mofitt and Stephen Shore for guidance and support. I thank the editor and two anonymous referees whose comments improved the paper. Thanks also to Peter Gottschalk, and the participants at several seminars and conferences for helpful comments and discussions. All remaining errors are mine.
} 


\section{Introduction}

Understanding how much idiosyncratic risk people face and how individuals respond to different types of risks is important for a number of reasons. There is an extensive literature analyzing individual's precautionary behavior under incomplete markets such as savings and labor supply. ${ }^{1}$ The implications of these models depend critically on the assessment of the levels of wage risk and the persistence of the shocks. From a policy perspective, in order to answer questions such as how government insurance programs should be optimally designed, one needs to have a clear picture of the the level and sources of risks being insured. For instance, the question of whether the government should provide insurance against "initial conditions" (such as growing up in a bad family environment) depends on the relative importance of initial conditions to labor market shocks later in life. Understanding how individuals respond to different types of risks is also important, as government insurance programs often have incentive impacts on individual's behavior against risks (e.g. Low and Pistaferri (2010)).

In most papers, changes in properly defined wage residuals represent shocks and different properties of permanent and transitory shocks allow researchers to use autocovariance structure of these residuals to identify the magnitude and persistence of idiosyncratic wage risks. ${ }^{2}$ With a few exceptions discussed below, most of the existing literature does not specify sources of wage shocks. With sources of wage shocks left unspecified, one cannot learn their relative importance, their dynamic behavior, or the economic consequence of these shocks. In the absence of such information, it is difficult to evaluate the welfare consequences of policies insuring against specific sources of shocks to income (such as unemployment insurance and active labor market programs). In addition, the changes of wages can be endogenous as a result of workers' choices. When shocks are mixed with endogenous choices, it is difficult to assess the true welfare cost of wage risk, derive empirical implications of precautionary behavior, and evaluate the true consequences of government policy interventions.

This paper aims to advance our understanding of wage risk along two dimensions. First, I distinguish two types of wage shocks, one type of shocks occurring at worker-firm match level and the other type occurring at individual level which applies to all firms and matches. The decomposition of wage risk

\footnotetext{
${ }^{1}$ Among others, see Deaton (1992); Carroll (1992); Gourinchas and Parker (2002) (precautionary savings) and Low (2005) (precautionary labor supply). See Heathcote, Storesletten, and Violante (2009) and Meghir and Pistaferri (2011) for excellent reviews.

${ }^{2}$ See, among others, Abowd and Card (1989); Baker and Solon (2003); Blundell, Pistaferri, and Preston (2008); Meghir and Pistaferri (2004); Moffitt and Gottschalk (2011); Jensen and Shore (2008); Heathcote, Perri, and Violante (2010).
} 
into match-specific and worker-specific wage risk is economic significant because they have very different implications to individuals' behavior and policy. For instance, contrary to shocks at individual level, negative shocks at match level do not mean permanent depreciation of individual's general productivity and may be recovered by workers through job mobility. If match-level risk is more important than individual-level risk, government policies aiming at improving worker-firm match quality and reducing labor market frictions are more effective than policies insuring against general productivity loss. Second, by modeling worker's job mobility decisions in response to labor market shocks, I show the value of job mobility as a channel of response to match-level risk facing employed workers. The value of job mobility depends critically on the cost of job change and the variation of wage shocks at worker-firm level. The model is also capable of recovering true wage risk that workers experience prior to job mobility, which may be quite different from the wage risk inferred from observed wages after job mobility.

To achieve these goals, I build and estimate a wage process jointly with a structural dynamic model of job mobility. The wage process features four independent and linearly additive components: a component which is predicted by personal characteristics, an individual component, a match component, and a transitory shock. The match component can be interpreted as job-specific human capital or idiosyncratic firm effect on wages. ${ }^{3}$ The match component and individual component follow parallel stochastic processes: each of them evolves from a permanent shock and a random growth factor. Shocks therefore represent permanent deviations from individual-specific wage growth profile. It is worth noting that the wages considered throughout this paper refer to real wages. Sticky nominal wages would show up as real wage cuts over time, and workers could be motivated to switch to other jobs that are willing to compensate for the cost of inflation. ${ }^{4}$

In a labor market with search frictions, there is a distribution of firms offering the same worker different values of a match. Employed workers are motivated to search on-the-job and to choose a better match component of the wage as they locate other jobs over time. They also face layoff risk and may also voluntarily quit to unemployment. When they switch employers, they have to pay a one-time switching cost, which captures unobservable non-wage factors affecting worker's job mobility decision. The model is estimated by method of simulated moments using longitudinal data of young male workers

\footnotetext{
${ }^{3}$ Empirically it is infeasible to distinguish pure firm effect from pure worker-firm match effect without employeremployee matched data.

${ }^{4}$ Section 3 presents empirical evidence on the extent of wage cuts and the correlation between wage cuts and job mobility in the data. Similar to Topel and Ward (1992), I find strong empirical evidence that workers' mobility decisions are correlated with job-specific wage changes in the past.
} 
from the 1996 panel of Survey of Income and Program Participation (SIPP). Under certain conditions, the model implies that only the match component is correlated with job mobility choices, which can be used to separately identify the match component from the person component in the wage residuals.

The key findings are summarized as the following. Wage risk at the match level accounts for the majority of the wage risk facing workers. For instance, among low-education (high-school educated) men, the variance of match-level shock $\left(\sigma_{\eta}^{2}\right)$ is $\frac{0.644}{100}$, whereas the variance of the person-level wage shocks is small and insignificantly different from zero. The fact that the majority of wage risk is at worker-firm level has three important implications. One is that job mobility is an important channel for individuals to react against negative wage shocks. The welfare gains of job mobility among higheducation individuals range from $8-9 \%$ of the average life-time value a job. The value of job mobility depends on the degree of frictions in the labor market: it is decreasing in the worker's switching cost and increasing in the probability of job offer arrival during employment. Therefore, labor market policies aiming at reducing worker's switching cost and increasing offer arrival probabilities are effective in protecting workers from negative match-level shocks. The second implication is that true wage risk, identified jointly from wage outcomes and mobility choices, is three times as large as the wage risk that is estimated using post-mobility wage information alone. For instance, among high-education men, true wage risk prior to job mobility is $\frac{0.89}{100}$, whereas the variance of permanent shocks identified from a canonical wage process is only $\frac{0.28}{100}$. Lastly, variations in the match-component of wages are the main driving force behind the increasing inequality over life. It suggests that policies aiming at improving worker-firm matches are at least equally important as education policies aiming to improving initial conditions.

To the best of my knowledge, this is the first paper which studies the welfare value of job mobility as a mechanism for worker to respond to labor market shocks. ${ }^{5}$ The value of job mobility in this context builds upon the premise that job mobility decisions are primarily affected by match-specific wage fluctuations. In a seminal paper, Topel and Ward (1992) find evidence that previous job-specific wage growth affects workers' job mobility decisions (holding the current wage and other observed characteristics fixed). However, they find this result "somewhat puzzling in light of our previous evidence that within-job wage growth approximates a random walk" (p.473). This suggests that one

\footnotetext{
${ }^{5}$ This paper also is related to the literature trying to understand channels available for individuals in response to labor market risk, such as Low (2005) (labor supply), Kaplan (2012) (within family), Blundell and Pistaferri (2003) (means-tested program), Gruber (1997) (unemployment insurance), Low and Pistaferri (2010) (disability insurance).
} 
needs to estimate a stochastic wage process jointly with worker's job mobility choices, which is the direction taken in this paper.

Two recent papers, Altonji, Smith, and Vidangos (2013) and Low, Meghir, and Pistaferri (2010), make important contribution to the literature by modeling earning dynamics and employment choices jointly. Low, Meghir, and Pistaferri (2010) estimate a wage process incorporating an individual's selection process between jobs and into and out of employment. Their estimates suggest that, once job mobility decisions are controlled for, the variance of permanent shocks is much lower. This suggests that what has been identified as permanent wage risk from typical error component model contains variability due to responses to shocks through job mobility. Altonji, Smith, and Vidangos (2013) construct a rich statistical model of earning dynamics from equations governing wage determination, hours of labor supply, job-to-job transition and transitions into and out of unemployment. They show that job mobility and unemployment, among other factors, play a key role in determining the variance of earnings over a career.

The current paper contributes to this line of research in a few dimensions. One important difference is that both Altonji, Smith, and Vidangos (2013) and Low, Meghir, and Pistaferri (2010) assume that the worker-firm match component of the wage does not vary over the duration of the job. Withinjob wage changes are assumed independent of worker's job mobility decision. Therefore, there is no match-specific wage risk except unemployment risk. One key feature of the current paper is to model wage dynamics within jobs and worker's selection across jobs. By doing so, it distinguishes wage risk that is particular to a job (worker-firm match) from wage risk applying to all jobs. Similar to Altonji, Smith, and Vidangos (2013) and Low, Meghir, and Pistaferri (2010), I find that the estimated variance of permanent shocks (from canonical models) is reduced when endogenous mobility is taken in account and match value is held constant within jobs. However, incorporating dynamic process of match within jobs yields a much higher wage risk facing workers prior to job mobility decisions, mainly from the large estimated match-level risk.

In this paper, the structural model is estimated jointly with the wage process, thereby imposing all the restrictions from the model on the evolution of the wage process. By contrast, in both Low, Meghir, and Pistaferri (2010) and Altonji, Smith, and Vidangos (2013), identification of the wage process relies on a reduced-form model of endogenous mobility decisions without imposing all the restrictions 
implied by a structural model. While estimating a descriptive statistical model may be attractive in many ways, welfare implications of job mobility and various types of risks and related counterfactual analysis require an estimated structural model. Low, Meghir, and Pistaferri (2010) evaluate welfare implications of different types of risks by using the estimated wage process from the reduced-form model and calibrating the remaining structural parameters in a life-cycle model of consumption, labor supply and job mobility. While the model in the current paper adds to their model in certain dimensions (such as switching cost and heterogeneous wage growth), it does not allow workers to save and ignores the availability of public insurance programs during unemployment. Since individual's response to wage risk will depend partly on the availability of either self-insurance such as savings or or public insurance, the welfare value of job mobility estimated in this paper is likely to be an upper bound.

A few recent papers in the structural job search literature also make important contributions to understanding wage dynamics, including Yamaguchi (2010); Postel-Vinay and Turon (2010); Bagger, Fontaine, Postel-Vinay, and Robin (2011); Lise, Meghir, and Robin (2012). While the emphasis of these papers are somewhat different from the current paper, these papers develop equilibrium job search model and analyze the determinants of individual wage dynamics. The current paper adds to this literature by assuming a more flexible and reduced-form wage process where there are two unobserved stochastic wage components evolving in parallel, each of which is subject to persistent shocks which are economically significant for the reasons mentioned previously. The tradeoff is that, to make the model and identification tractable, the decision of job mobility is determined in partial-equilibrium and omitted some important features which the other papers address.

The rest of the paper proceeds as follows. Section 2 describes the wage process and the dynamic model of job mobility. Section 3 presents the data and descriptive evidence which motivates this study. Section 4 discusses the estimation and identification strategy. Section 5 presents estimation results. Section 6 presents implications of the structural model on the welfare value of job mobility, the welfare costs of different types of risks and sources of wage growth and inequality. Section 7 concludes.

\section{The Model}

I build a dynamic model of job search, in which an individual makes job mobility and employment decisions jointly. The assumptions of the model are as follows. An individual $i$ maximizes the expected 
present value of utility over a finite horizon, subject to a wage process specified below. In each decision period $(t)$, the individual (both when unemployed and when employed) search for job opportunities at no cost. At the beginning of each period, if the individual is employed, she makes the following discrete choice: move to a different job if an offer arrives, become unemployed, or stay with the current job. If the individual is unemployed, she chooses from becoming employed (if an offer arrives) or remain unemployed. Details of the choice structure are contained in Section 2.2. Below I begin by describing the wage process.

\subsection{The Wage Process}

The life-cycle wage process for the individual $i$ employed by firm $j$ in period $t$ is:

$$
\begin{aligned}
& \ln \widetilde{w}_{i j t}=\ln w_{i j t}+v_{i t} \\
& \ln w_{i j t}=\beta_{0}+a_{i j t}+u_{i t} \\
& a_{i j t+1}=\left\{\begin{array}{l}
a_{i j t+1}^{l}, \quad \text { if no job change between } t \text { and } t+1 \\
a_{i j^{\prime} t+1}^{o}, \quad \text { if there is job change between } t \text { and } t+1
\end{array}\right. \\
& a_{i j t+1}^{l}=a_{i j t}+c_{i}+\eta_{i j t+1}, a_{i j^{\prime} t+1}^{o} \sim N\left(0, \sigma_{a_{0}}^{2}\right) \\
& u_{i t+1}=u_{i t}+\delta_{i}+\zeta_{i t+1}
\end{aligned}
$$

Assume that

$$
\begin{array}{r}
\zeta_{i t} \sim N\left(0, \sigma_{\zeta}^{2}\right), \eta_{i j t} \sim N\left(0, \sigma_{\eta}^{2}\right) \\
E\left(v_{i t}\right)=0, \operatorname{var}\left(v_{i t}\right)=\sigma_{v}^{2} \\
u_{i 0} \sim N\left(0, \sigma_{u_{0}}^{2}\right)
\end{array}
$$

with orthogonality between these error terms. $\ln \widetilde{w}_{i j t}$ is the observed real log hourly wage for worker $i$ employed by firm $j$ in period $t$ and $v_{i t}$ is an error term combining a transitory component with measurement error (more on the latter below). For an employed worker, the log wage residual (after taking out the constant term $\beta_{0}$ ) is decomposed into three components: an individual component $u_{i t}$, a match component $a_{i j t}$ between firm $j$ and worker $i$, and the transitory shock $v_{i t}$. The former two 
components evolve independently under two parallel stochastic processes, both with the same random walk and random growth structure described below. All parameters of the wage process are specific to the completed education level of the individual.

The individual component $\left(u_{i t}\right)$ measures the worker's general productivity regardless of his employer. It evolves over the life-cycle from an identically and independently distributed permanent random shock $\zeta_{i t}$ and a random growth factor $\delta_{i} . \sigma_{u_{0}}^{2}$ measures the initial heterogeneity of general productivity. The individual component corresponds to the concept of permanent wage in the literature, which is usually thought of as representing return to skill or flow from human capital. The heterogeneous growth in individual component of wage captures heterogeneous return to work experience, perhaps through differential learning ability to general skills or human capital investment. ${ }^{6}$

Parallel to the individual component and prior to selection between jobs, the match component follows a random walk process with a random growth factor. Let $a_{i j t+1}^{l}$ be the latent match at $t+1$ prior to job mobility ("l" represents latent). It evolves from a random growth factor (drift) $c_{i}$ and a permanent shock $\eta_{i j t}$ which is identically and independently distributed across firms, workers and time. One interpretation of the match component is that it is an idiosyncratic firm effect which is complementary to individual productivity. From the perspective of human capital theory, the match component can also be regarded as job-specific human capital. The random growth factor $c_{i}$ measures the individual-specific growth of match value for an employed worker, which can be thought of as return to job tenure (or firm-specific human capital). The shock to the match component then represents a worker-firm specific permanent deviation from the mean growth rate. This would happen, for example, when in a particular year the firm does not provide enough training to enhance worker's firm-specific skills (negative $\eta_{i t}$ ), or it adopts a new technology that is complementary to worker's productivity (positive $\eta_{i t}$ ). In general it consists of both a pure match-specific shock and a pure firm-specific shock, although without firm level data, distinguishing between these is not feasible. More broadly, the match component can be interpreted as any factor that affects the worker's productivity with the current firm but not after he leaves for other firms. The random growth factor and permanent shocks to the match component are accumulating only over the current job tenure and will "vanish" after a job change. ${ }^{7}$

\footnotetext{
${ }^{6}$ In periods of unemployment, the individual component is kept constant. This assumes away any exogenous depreciation of skills following job loss. See below for details.

${ }^{7}$ It is important to emphasize that the new accepted match would be positively correlated to the old match because of selection. It is only in this sense that firm-specific human capital may be partially transferable between jobs.
} 
A discrete factor representation is used to characterize the joint distribution of the random growth factors (e.g. Heckman and Singer (1984)). The vector $\left(c_{i}, \delta_{i}\right)$ follows a discrete probability distribution with two points of support, each of which reflects the unobserved "type" of the individual. $c_{i}$ and $\delta_{i}$ can be correlated; for instance, an individual who has a high return to tenure may also have a large wage gain from an additional year of experience. ${ }^{8}$ Match- and individual-specific log wage shocks are assumed to follow normal distributions with zero means and variances $\sigma_{\eta}^{2}$ and $\sigma_{\zeta}^{2}$, respectively .

A job offer with match-specific wage $a^{o}$ ("o" stands for "offer") is a random draw from a stationary offer distribution. I assume that it follows a normal distribution with mean zero and variance $\sigma_{a_{0}}^{2}$. Because of the growth profile in the person-component of wage (due to $\delta_{i}$ ), the offered levels of wages would be mean-shifting with worker's labor market experience. Offered matches are assumed uncorrelated with worker's individual wage component, and hence each firm has a constant return to labor technology and there is no sorting in the labor market.

When worker $i$ receives an offer from firm $j^{\prime}$ at time $t$, prior to making a job mobility decision, the worker is perfectly informed of his general productivity $\left(u_{i t}\right)$, match-specific productivity $\left(a_{i j t}^{l}\right)$ if he chooses to stay and the value of the offer $\left(a_{i j^{\prime} t}^{o}\right) .{ }^{9}$ At any time, workers have perfect information about their current match value, the expectation of future match values, and the distribution of the match component in the labor market, but information on other job locations and their associated match value must be obtained through search. I assume that none of the shocks to the $u_{i t}$ and $a_{i j t}$ are anticipated by the worker so they represent wage uncertainty. ${ }^{10}$

Transitory shocks are identically and independently distributed across individual and time. The transitory shocks represent exogenous wage shocks with no persistence, at either the worker-firm match level or the person level. It also includes classical measurement errors on reported wages. I assume that transitory shocks affect wages after the mobility decision is made in each period, and therefore, given it is serially uncorrelated, it is unrelated to job mobility choices. This assumption simplifies the solution to the dynamic programming problem to be introduced in the following section. It is

\footnotetext{
${ }^{8}$ The age profile of wages will be captured through the random growth factors $\delta_{i}$ and $c_{i}$ and through job mobility. This is different from the literature treating wage growth as exogenous, where the means of random growth factors are normalized to 0. See Section 4 for more discussions.

${ }^{9}$ Another set of search models develops the idea that the value of a match is not known when firm and worker meet but is updated ex-post as more information arrives. See Jovanovic (1979).

${ }^{10}$ This excludes the possibility that parts of these random shocks may be known to workers in advance. See Cunha, Heckman, and Navarro (2005).
} 
potentially interesting to allow transitory shocks to be serially correlated and to operate at both the person and match level. ${ }^{11}$ In this case, both permanent and transitory match-level shocks enter into worker's information set prior to job mobility decisions. Besides increasing computational burdens, it is difficult to justify a homogeneous correlation restriction on the transitory component of wages applying to all workers' information sets. For the match-level wage process, the distinction between permanent and transitory is less important: permanent match shocks, albeit permanent from the view of workers, can be transitory ex-post if job-to-job transitions occur quickly. For these reasons, I have assumed that all shocks at the match level are permanent ex-ante in the worker's information set. Given that common sources of transitory shocks considered important in the literature (such as transition between employment and unemployment, short job spells) are modeled explicitly below, I interpret the transitory shocks in this paper as measurement errors.

\subsection{The Model of Job Mobility}

Utility function. The baseline utility function is specified as the following:

$$
u_{i j t}=\ln \left(w_{i j t}\right) P_{i t}+\alpha_{h}\left(1-P_{i t}\right)-k_{i} M_{i t}
$$

The individual's utility depends on her $\log$ wage $\left(\ln \left(w_{i j t}\right)\right)$ if she is working $\left(P_{i t}=1\right)$. The wage evolves subject to the stochastic process specified above. He faces direct utilities of unemployment $\left(\alpha_{h}\right)$. This parameter should in general be positive, reflecting the value of additional leisure relative to work. $k_{i}$ denotes the utility loss for the individual if she switches jobs $\left(M_{i t}=1\right)$. Switching costs are unobservable non-wage factors affecting worker's job mobility decision.

Intertemporal Optimization Problem. In period $t_{0}$, the individual maximizes the expected present discounted value of utility from the current period to the end of the time horizon $T$

$$
\max E_{t_{0}} \sum_{t=t_{0}}^{T} \Gamma^{t-t_{0}} u_{i j t}
$$

\footnotetext{
${ }^{11}$ Many papers, e.g. Moffitt and Gottschalk (2011); Haider (2001); Meghir and Pistaferri (2004), show that there is some serial correlation over time in the transitory shocks. However, all these papers do not model worker's job-to-job selection. Job mobility is arguably the main contribution to transitory shocks (Gottschalk and Moffitt, 1994).
} 
where $\Gamma$ is the discount factor, $T$ is the length of the decision horizon, and $E_{t_{0}}$ is the expectations operator conditional on information available in period $t_{0}$.

All individuals begin their lives in the unemployment state. Let $\boldsymbol{\alpha}_{i}$ denote the set of state variables summarizing the individual's characteristics, where $\boldsymbol{\alpha}_{i} \equiv\left\{k_{i}, c_{i}, \delta_{i}, u_{i 0}\right\}$. The value of nonemployment for the individual in period $t$ is defined as

$$
V_{t}^{n}\left(u_{i t}, \boldsymbol{\alpha}_{i}\right)=\alpha_{h}+\left(1-\lambda^{n}\right) \Gamma E\left[V_{t+1}^{n}\left(u_{i t+1}, \boldsymbol{\alpha}_{i}\right)\right]+\lambda^{n} \Gamma E \max \left[V_{t+1}^{n}\left(u_{i t+1}, \boldsymbol{\alpha}_{i}\right), V_{t+1}^{e}\left(a_{i j t+1}, u_{i t+1}, \boldsymbol{\alpha}_{i}\right)\right]
$$

where $\lambda^{n}$ is the probability that an offer arrives in each period and $V_{t+1}^{e}\left(a_{i j t+1}, u_{i t+1}, \boldsymbol{\alpha}_{i}\right)$ is the value of employment if the worker is offered a job with match productivity of $a_{i j t+1}$. In periods of nonemployment, the individual wage component is held constant (i.e. $\left.u_{i t}=u_{i t+1}\right) .{ }^{12}$ The job offer is acceptable to the individual provided that $V_{t+1}^{e}\left(a_{i j t+1}, u_{i t+1}, \boldsymbol{\alpha}_{i}\right)$ is larger than $V_{t+1}^{n}\left(u_{i t+1}, \boldsymbol{\alpha}_{i}\right)$.

The value function of employment with the firm $j$ in period $t$ is given by ${ }^{13}$

$$
\begin{aligned}
& V_{t}^{e}\left(a_{i j t}, u_{i t}, \boldsymbol{\alpha}_{i}\right) \\
& =\ln \left(w_{i j t}\right)+\lambda^{e}(1-\rho) \Gamma E \max \left[V_{t+1}^{e}\left(a_{i j t+1}, u_{i t+1}, \boldsymbol{\alpha}_{i}\right), V_{t+1}^{e}\left(a_{i j^{\prime} t+1}, u_{i t+1}, \boldsymbol{\alpha}_{i}\right)-k_{i}, V_{t+1}^{n}\left(u_{i t+1}, \boldsymbol{\alpha}_{i}\right)\right] \\
& +\left(1-\lambda^{e}\right)(1-\rho) \Gamma E \max \left[V_{t+1}^{e}\left(a_{i j t+1}, u_{i t+1}, \boldsymbol{\alpha}_{i}\right), V_{t+1}^{n}\left(u_{i t+1}, \boldsymbol{\alpha}_{i}\right)\right]+\rho \Gamma E\left(V_{t+1}^{n}\left(u_{i t+1}, \boldsymbol{\alpha}_{i}\right)\right)
\end{aligned}
$$

where $\lambda^{e}$ is the job offer arrival rate when the individual is employed and $\rho$ is the exogenous layoff probability in each period. When the individual accepts an external offer, he pays a switching cost of $k_{i}$ and his match component will be the match value offered by the new firm $\left(a_{i j^{\prime} t+1}\right)$. The dynamics of state variables $a_{i j t}$ and $u_{i t}$ follow the wage process specified previously. For instance, if the individual continues with the same job in the next period, her wage paid by the current employer then adjusts to a new level to absorb the returns to tenure and experience, permanent shocks to the individual and match components of wages, and any transitory shock. The worker may also choose to quit to unemployment following large negative shocks to either $a_{i j t}$ or $u_{i t}$.

\footnotetext{
${ }^{12}$ For the sample of young men focused in the paper, the unemployment rate is low (less than $5 \%$ overall). For other demographic groups such as women, allowing for skill depreciation in periods of unemployment might well be an important extension.

${ }^{13}$ Since the decision period is discrete, additional restrictions are placed on the timing of the events. In particular, it is assumed that the individual is only able to receive a job offer conditional on the current job not being displaced. When the individual is displaced, she has to remain unemployed for at least one period.
} 
Analysis of the Model. The employment decision can be characterized by a threshold reservation value where the worker is employed if the offered match value is larger than the threshold. The reservation match $\left(g_{t}\left(u_{i t}, \boldsymbol{\alpha}_{i}\right)\right)$ is defined implicitly by:

$$
V_{t}^{n}\left(u_{i t}, \boldsymbol{\alpha}_{i}\right)=V_{t}^{e}\left(g_{t}\left(u_{i t}, \boldsymbol{\alpha}_{i}\right), u_{i t}, \boldsymbol{\alpha}_{i}\right)
$$

where the reservation match for employment depends on the individual permanent component and unobserved type of the individual. It is straight-forward to show that $g_{t}\left(u_{i t}, \boldsymbol{\alpha}_{i}\right)$ is decreasing in $u_{i t} .{ }^{14}$ When the individual permanent component is high, an unemployed individual has a high chance of accepting an offer and an employed worker has a small probability of quitting to unemployment following a negative match-level shock.

Job mobility decision can be characterized by a threshold reservation value where the worker chooses to move if the offered match is larger than the threshold. For a worker currently employed by firm $j$, the reservation match is defined implicitly by:

$$
V_{t}^{e}\left(a_{i j t}, u_{i t}, \boldsymbol{\alpha}_{i}\right)=V_{t}^{e}\left(h_{t}\left(a_{i j t}\right), u_{i t}, \boldsymbol{\alpha}_{i}\right)-k_{i}
$$

The worker chooses to move if and only if there is an offer such that $a_{i j^{\prime} t}^{o}>h_{t}\left(a_{i j t}\right) .{ }^{15}$ The following proposition characterizes worker's reservation match value for moving:

Proposition 1. For a worker of unobserved type $\boldsymbol{\alpha}_{i}$ with individual wage component $u_{i t}$, the reservation match for job mobility, $h_{t}\left(a_{i j t}\right)$ satisfies the following properties for all $t=1 \ldots T-1$, :

(1) $h_{t}\left(a_{i j t}\right)>a_{i j t}$ if $k_{i}>0$ and $h_{t}\left(a_{i j t}\right)=a_{i j t}$ if $k_{i}=0$.

(2) $0<\frac{\partial h_{t}\left(a_{i j t}\right)}{\partial a_{i j t}}<1$.

Proof. See Appendix A.

\footnotetext{
${ }^{14}$ The proof is very similar to the proof of Lemma 2 in Appendix A. It builds on the fact that both the values of unemployment and employment are monotonically increasing in $u_{i t}$. Moreover, for one unit change in $u_{i t}$, the value of employment increases more than the value of unemployment.

${ }^{15} \mathrm{In}$ a previous version of the paper where unemployment is not in the choice set, the reservation match can be characterized as a function of only $\left\{a_{i j t}\right\}$. This is because the individual-specific component is linearly additive to and independent from the match component. In the current model allowing for voluntary quits to unemployment and switching cost, the reservation wage for employment depends on the individual wage component $\left(u_{i t}\right)$. Therefore, in principle, comparison between the value of two jobs should depend on all state variables in the model. However, the estimated variance of individual-level shocks is too small to generate voluntary quits to unemployment (Section 6.3). Therefore, as a local approximation, changes in $u_{i t}$ does not affect the reservation match for job mobility for a given individual.
} 
When there is no switching cost, the job selection rule is simply based on the difference between the offered match and the current match value (as in, e.g. Burdett (1978)). Job mobility decision is only driven by the current value of match component. For a worker whose switching cost is positive, the worker's reservation match value is always greater than the match value with the current firm (which is the reservation match when switching cost is zero). The "premium" in the reservation match includes the expected discounted long-run compensation of the switching cost that has to be paid upon moving. Switching cost, therefore, influence the extent of labor market inefficiency besides search friction. The second property indicates that the reservation match is monotonically increasing in the quality of the current match and that the rate of increase is decreasing in $a_{j t}$ grows. This means that, the lower the current match quality is, the larger the premium of $h_{t}\left(a_{i j t}\right)$ is (above $a_{i j t}$ ). The economic intuition is that a low-match-quality worker expects frequent job changes in the future. Conditional on the individual's switching cost, the optimal strategy is to set a large gap between the reservation match and the match paid by the current firm. By setting the gap large, the individual avoids paying too much switching cost before reaching a high wage level. ${ }^{16}$

An important insight from the last reservation match property is that, following a negative match shock, the worker's reservation match becomes lower than the reservation match without the shock. There is a set of wage offers that are acceptable after the match-level shock which would not have been acceptable without the match-level shock. This is how job mobility arises as a channel of ex-post response to wage risk. The value of job mobility depends on how the match-level shock affects the worker's job mobility decision, holding the reservation wage fixed at each period. In Section 6.1, I formally define and quantify job mobility as a means of responding to shocks in the labor market. Note that the welfare value of job mobility defined here is not the same as shutting down all job mobility, because with random job offers and on-the-job search, there is job mobility even if workers were not to move because of match shocks. This discussion also highlights the economic importance of modeling the dynamics of the match-specific wage $a_{j}$ and the person-specific wage $u$ separately. If match quality $a_{j}$ is constant within jobs, then job mobility would not be a useful channel to act against wage shocks.

\footnotetext{
${ }^{16}$ See also Hey and McKenna (1979); Van Der Berg (1992) for a similar point in a different context.
} 


\section{Empirical Evidence}

\subsection{Data and Summary Statistics}

The data set I exploit is the 1996 panel of Survey of Income and Program Participation (SIPP). It is a four-year panel comprising 12 interviews (waves). Each wave collects comprehensive information on demographics, labor market activities and types and amounts of income for each member of the household over the four-month reference period. There are two main advantages of using the SIPP. One is that it has a short recall period, making it an ideal data set to study short-term employment dynamics that are very common among young workers. ${ }^{17}$ The other advantage is that the SIPP contains a unique job ID for every job an employed worker had through the sample period. It records job specific wages and hours at each interview date (every four months), allowing researchers to obtain the precise wage changes at the time when job transitions take place. These features make it an attractive data set to study short-term job mobility and wage dynamics.

The original SIPP 1996 panel has 3,897,177 person-month observations. ${ }^{18}$ I drop females, full-time students, the self-employed, the disabled, those completing fewer than nine interviews and those who are recalled by previous employer after a separation. I trim the population whose real wage falls into the top and bottom $1 \%$ of the real wage distribution by wave. I focus on the primary job, which is defined as the job generating the most earnings in a wave. Although SIPP has monthly information on job changes and earnings, the time unit in the analysis of this paper is four months (a wave). This avoids the seam bias if we were using monthly variables. Real monthly earnings and the wage is derived by deflating the reported monthly earnings and wage by monthly US urban CPI. The reported hourly wage rate is used whenever the worker is paid by hour. For these workers, the real wage per wave is the mean of monthly real wage over the four months. For workers who are not hourly paid, their real wages are obtained by dividing real earnings per wave by reported hours of labor supply per wave. ${ }^{19}$ Job change is identified from a change in job ID between waves. If an individual is unemployed through the wave, no job ID would be assigned. In the first wave of SIPP, respondents are asked the starting

\footnotetext{
${ }^{17}$ In the selected sample, if a worker is observed to change jobs in a given calendar year, $19 \%$ of them would experience multiple job changes within the same calendar year. This means that job mobility observations at annual frequency understate the extent of job-to-job transitions by about a fifth.

${ }^{18}$ Note that, due to attrition, not all individuals complete 12 interviews.

${ }^{19}$ For each month, respondent reports hours of work per week and how many weeks worked. Monthly labor supply is calculated as hours per week $\times($ weeks worked/weeks in month $) \times 4.33$
} 
date of the present job. I use this information to construct correct job tenure for workers with elapsed job duration when they are first sampled.

I construct two separate panels, one consisting of low-education individuals (those with high school education) and the other including high-education individuals (those with college education). Each panel contains individuals aged between 23 and 35 observed who are observed for eight consecutive waves in the sample. ${ }^{20}$ The final samples consist of 938 men in the high-education sample and 755 men in the low-education sample.

Summary statistics are provided in Table 1 . Table 2 reports the distribution of total number of observed job changes in the sample. The initial life-cycle period refers to the periods of potential experience observed in the first sample period. Overall, nearly $45 \%$ of the workers switch jobs at least once in the four-year sample period. The extent of job-to-job transitions decreases monotonically with potential experience of the individual. For instance, among the most experienced, only $30 \%$ of the individuals made at least one job change within the sample period. In contrast, majority of the individuals who recently entered the labor market made at least one job change by the end of the sample period.

\subsection{Wage Growth and Job Mobility: Descriptive Evidence}

The model features endogenous within-job wage change which is correlated with worker's job mobility decision. In this section, I present a set of descriptive evidence addressing the following questions: First, what is the pattern of within-job wage growth and, in particular, how common are real wage cuts? Second, what is the empirical relation between within-job wage growth and subsequent job mobility? Are workers who experience within-job wage cuts more likely to change jobs? The empirical evidence provided here does not carry any structural interpretation. Nevertheless, descriptive regressions in this section are useful benchmarks to evaluate the assumptions and implications of the model.

Figure 1 presents the distribution of within- and between-job wage growth. Top panel shows real wage growth calculated as the change in $\log$ real wages every four months. ${ }^{21}$ Two features of the picture are clear. First, between-job wage growth has larger variation than within-job wage growth.

\footnotetext{
${ }^{20}$ Job mobility is most frequent and is the most important way for wage growth in early careers (Topel and Ward, 1992). Since the SIPP is a short panel and the expected college completion age is 23 , this selection criteria also ensures that the highest completed education level is obtained for each individual.

${ }^{21}$ Throughout this section, wage refers to real wage unless noted otherwise.
} 
Second, both within-job and between-job real wage cuts are very common. Around $45 \%$ of job-to-job transitions end up with wage cuts, and about half of within-job wage growths are negative. Majority of the within-job wage cuts are small in magnitude. For instance, the median within-job real wage cut is merely of $1.3 \%$ per period. There remains, however, a substantial portion of within-job wage growth showing significant drops. Among the within-job real wage cuts, $25 \%$ of those include wage declines of $12 \%$ or more between waves. Wage cuts between jobs are much greater in magnitude: the median between-job wage decline is close to $20 \%$. Measurement error may be an important contributor, which is accounted for in the wage process and discussed later. Part of the real wage change could also be due to the stickiness of wages which are not immediately keeping up with a rising cost of living. The bottom panel of Figure 1 shows the distribution of nominal wage growth between and within jobs. While the majority of the workers experience nominal wage growth, the number of workers that had a nominal wage cut remains substantial.

Next I investigate the empirical relation between within-job wage growth and worker's subsequent mobility choice. Specifically, suppose we have a worker employed by firm $j$ at time $t-2$ and $t-1$. The primary question of interest is whether a worker whose within-job wage growth is low in period $t-1$ is more likely to move to another job in $t$. Table 3 reports the estimates from a linear probability model of job mobility on lagged wage growth (under various assumptions of covariates). In column (1), binary variable of job mobility is regressed on one-period lagged within-job wage growth without any covariates. In column (2) I add lagged job tenure and in (3) I further control for the two-period lagged level of the wage and lagged experience as explanatory variables. Columns (4) builds on the specification in column (3) by adding individual fixed effects. This controls for individual unobservables that jointly affect wage growth and mobility choices. In columns (5), I also add two-period lagged within-job wage growth and control for wage level in period $t-3$.

In each specification, the coefficient on within-job wage growth in $t-1$ is negative and statistically significant. ${ }^{22}$ This means that workers who experience smaller within-job wage growth are more likely to change jobs in the coming periods. For instance, after controlling for observable characteristics of the worker-firm match (such as wage levels and job tenure), a 10\% decline in the current wage increases the probability of a job change in the next period by $0.68 \%$ (column 3). Controlling for individual

\footnotetext{
${ }^{22}$ With classical measurement error, the coefficient estimates on within-job wage growth term is biased toward zero, indicating that the true empirical relation between wage growth and job mobility is even stronger.
} 
unobserved heterogeneity leads to even larger estimates (column 4). The additional coefficient on within-job wage growth in $t-2$ (column 5$)$ is also negative and significant. These results indicate that within-job wage changes are correlated with future job mobility, even after controlling for individual unobserved heterogeneity. The strong correlation between lagged within-job wage growth and job mobility is informative of the potential important role of the match-level shocks. One of the main tasks of the structural model is to decompose the within-job wage variations due to match- and individuallevel shocks, random growth factors and measurement errors and to account for endogenous selection over jobs (beyond the individual fixed effects).

\section{Identification and Estimation Strategy}

I assume that the distribution of switching costs is discrete. Switching cost types assume the values $0<k_{2}<k_{1}$, with the probability that an individual is a low switching-cost type (type 2) to depend on observable characteristics in the following manner:

$$
\beta(Z)=\frac{\exp \left(\gamma_{0}+\gamma_{1} Z_{1}+\gamma_{2} Z_{2}\right)}{1+\exp \left(\gamma_{0}+\gamma_{1} Z_{1}+\gamma_{2} Z_{2}\right)}
$$

where $Z_{1}$ is an indicator variable that takes the value 1 when the individual is married and $Z_{2}$ is an indicator variable that takes the value 1 if she owns a house. ${ }^{23}$

The parameter set consists of utility function parameter $\left(\alpha_{h}\right)$, wage equation parameters $\left(\beta_{0}, \sigma_{u_{0}}^{2}, \sigma_{a_{0}}^{2}, \sigma_{\eta}^{2}, \sigma_{\zeta}^{2}, \sigma_{v}^{2}\right)$, job search parameters $\left(\lambda^{e}, \lambda^{n}, \rho\right)$ and type-specific parameters $\left(c_{1}, c_{2}, \delta_{1}, \delta_{2}, \pi_{2}, k_{1}, k_{2}, \gamma_{0}, \gamma_{1}, \gamma_{2}\right)$. The tuple $\left(c_{i}, \delta_{i}\right)$ differs across types so the unobserved random growth factors can be correlated. The discount factor $\Gamma$ is not estimated and held fixed at 0.92.

\subsection{Identification}

I begin this section by illustrating why modeling job mobility decisions is necessary to identify the true wage risk. Suppose the log wage consists of only the match-specific component subject to permanent shocks. Figure 2 demonstrates two possible wage dynamics for a given worker. Prior to time $t$, the wage is $a_{0}$. At the beginning of period $t$, he suffers a permanent negative match specific shock $\eta$, and

\footnotetext{
${ }^{23}$ Both variables are measured on the first observation date and is assumed time-invariant starting from the beginning of life.
} 
his new wage is $a_{1}=a_{0}-\eta$. The permanent wage drop considered here stems from a pure idiosyncratic firm effect and does not mean a depreciation of general individual productivity. In the absence of job mobility, his wage is expected to remain at $a_{1}$ for the rest of his working life.

I consider two scenarios. First, suppose a job offer valued $a^{o}$ arrives at $t+1$ (left panel of Figure 2 ). Assuming a positive switching cost, if the new offer is greater than his reservation match $h\left(a_{1}\right)$, he would switch to the new job and earn a wage rate at $a_{2}=a^{o}$. In this case, the wage increase from $a_{1}$ to $a_{2}$ results from an endogenous job mobility decision rather than wage risk, a point emphasized by Low, Meghir, and Pistaferri (2010). Moreover, by changing jobs, the worker manages to turn the initial permanent wage $\operatorname{shock}(\eta)$ into one that is effectively partly transitory and partly permanent. Only for a worker who remains at $a_{1}$ for a long time is the initial shock correctly identified. The ex-post(observed) persistence of the shocks depends on how quickly a worker could improve his match by changing jobs. Since the probability of job changes is inversely related to the quality of the contemporaneous match, the model implies that match-specific shocks would appear more persistent for workers of better match quality and less persistent for workers of lower match quality. When decomposing the variation of observed wage changes, the contribution from permanent shocks should then be larger for workers of higher match quality. This is in line with empirical evidence from the existing literature. ${ }^{24}$ The right panel of Figure 2 depicts a second match dynamic in a similar setting. The only difference is that the worker is able to locate a better job within period $t$. If the worker takes the job, the observed wage rate in period $t$ becomes $a_{2}$ which underestimates the magnitude of true wage shock. The observed average wage per period alone mitigates initial wage risk facing workers, as it is combined with worker's response to latent shocks. The variance of permanent match-level shocks, $\sigma_{\eta}^{2}$, measures wage risk prior to job mobility.

The arguments for model identification are given below. The dynamic model of job mobility can

\footnotetext{
${ }^{24}$ For example, taking estimates from Table I and III of Meghir and Pistaferri (2004), a simple calculation shows that for college graduates, the variance of permanent shock account for $67 \%$ of variance of (unexplained) earnings growth, but the number drops to $27 \%$ for high school graduates and $20 \%$ for high school dropouts. This is consistent with implications from the model, if one believes that more educated workers acquire job-specific skills quicker and build up a higher match on average.
} 
be formulated as the Roy model:

$$
\begin{aligned}
& \ln w_{i j t}=\beta_{0}+a_{i j t}^{l}+u_{i t}+v_{i t} \\
& \ln w_{i j^{\prime} t}=\beta_{0}+a_{i j^{\prime} t}^{o}+u_{i t}+v_{i t}
\end{aligned}
$$

where as previously defined, $\ln w_{i j t}$ is the log wage for an individual $i$ employed by current employer $j$ in period $t$ and $\ln w_{i j^{\prime} t}$ is the offered $\log$ wage from firm $j^{\prime}$. Assuming no switching cost, the offer acceptance rule is simply based on the difference between the offered match and the current match value:

$$
\begin{aligned}
& J_{i t}^{*}=a_{i j^{\prime} t}^{o}-a_{i j t}^{l} \\
& J_{i t}=\left\{\begin{array}{l}
1 \text { if } J_{i t}^{*}>0 \\
0 \text { elsewhere }
\end{array}\right.
\end{aligned}
$$

$\ln w_{i j t}$ is observed when $J_{i t}=0$ and $\ln w_{i j^{\prime} t}$ is observed when $J_{i t}=1$. Given the distributional assumptions of the error terms laid out in Section 2, we know that $a_{i j t}^{l}$ is normally distributed conditional on $a_{i j t-1}$ (since $\eta_{i j t}$ is normally distributed) and $a_{i j^{\prime} t}^{o}$ is drawn from an independent normal distribution. ${ }^{25}$ Conditional on the match- and individual-level wages at the beginning of period $t$, the following moment conditions using data from period $t$ identify the parameters: $P\left(J_{i t}=1\right), E\left(\ln w_{i j t} \mid J_{i t}=\right.$ $0), E\left(\ln w_{i j^{\prime} t} \mid J_{i t}=1\right), \operatorname{var}\left(\ln w_{i j t} \mid J_{i t}=0\right), \operatorname{var}\left(\ln w_{i j^{\prime} t} \mid J_{i t}=1\right)$. This gives us five equations in four unknowns $\sigma_{\zeta}^{2}+\sigma_{v}^{2}, \sigma_{\eta}^{2}, \sigma_{a_{0}}^{2}$, and $\beta_{0}$. Note that, with one period of data, it is not possible to separately identify the variance of individual-level permanent shocks $\left(\sigma_{\zeta}^{2}\right)$ from measurement error $\left(\sigma_{v}^{2}\right)$. Like most papers in the wage dynamics literature, a panel data is required. Moments based on the autocovariances of wages are used to identify these two parameters separately.

When there are costs of switching jobs, the job mobility decision can be formulated as:

$$
J_{i t}^{*}=V_{t}^{e}\left(a_{i j^{\prime} t}, u_{i t}, \boldsymbol{\alpha}_{i}\right)-V_{t}^{e}\left(a_{i j t}, u_{i t}, \boldsymbol{\alpha}_{i}\right)-k_{i}
$$

\footnotetext{
${ }^{25}$ These parametric identification assumptions are sufficient to identify the Roy model (Heckman and Honore, 1990). Note that, since $u_{i t}$ does not enter the job selection rule, distributional assumptions on $u_{i t}$ is not necessary to identify the model.
} 
where $k_{i}$ is the job switching cost which does not affect potential wages regardless of mobility decision. Identification arguments follow the previous case without switching cost, except that exclusion restrictions are required to identify the switching cost parameters. Marital status $\left(Z_{1}\right)$ and house ownership $\left(Z_{2}\right)$ are excluded variables from the wage equations.

The panel structure of the data helps identify the parameters of permanent unobserved heterogeneity (modeled in the form of discrete types). For instance, the autocovariance function of job mobility helps to separately identify the heterogeneity in the return to tenure and the heterogeneity in match-level shocks $\left(\sigma_{\eta}^{2}\right)$. To see this, Figure 3 plots the simulated autocovariance of mobility at different lags, under three different combinations of $\sigma_{\eta}^{2}$ and $\sigma_{c}^{2}$ while holding the rest of the parameters fixed. ${ }^{26}$ While both greater $\sigma_{\eta}^{2}$ and $\sigma_{c}^{2}$ lead to an increase in the covariance of mobility across different lags, the contribution from $\sigma_{\eta}^{2}$ relative to $\sigma_{c}^{2}$ quickly declines as the lag grows. When the lags are sufficiently long, the autocovariance of mobility is affected by $\sigma_{c}^{2}$ but not by $\sigma_{\eta}^{2}$. Therefore, long autocovariance of job mobility identifies $\sigma_{c}^{2}$. Among workers, $\sigma_{\delta}^{2}$ and $\sigma_{\zeta}^{2}$ imply that the autocovariance of person-level wages grows nonlinearly and linearly, respectively, with time locations. Hence they are identified by fitting a quadratic and linear trend on autocovariance (Guvenen, 2007).

The labor market friction parameters can be identified using information from the observed wage distribution (Flinn and Heckman, 1982). Intuitively, if the rate of employment is low, a relatively untruncated distribution of observed wages would imply a low job offer arrival probability $\left(\lambda^{n}\right)$, while a heavily truncated distribution would imply a high taste for unemployment (i.e., high work reservation wage). The offered wage distribution can be recovered from the truncated distribution of observed wages due to the log-normal distributional assumption (which satisfies the identification condition in Flinn and Heckman). Then, the probability of on-the-job offer arrival $\left(\lambda^{e}\right)$ can be identified from the probability of switching jobs.

\subsection{Estimation Strategy}

The model is estimated by the Method of Simulated Moments (MSM). Each decision period in the model corresponds to one wave (four months) in the data. In each iteration in the parameter space, computation of the simulated moments consists of nested loops. In the outer loop, the value functions

\footnotetext{
${ }^{26}$ For the purpose of illustration, in the simulation here, the distribution of $c$ is assumed normally distributed with mean zero and variance $\sigma_{c}^{2}$.
} 
in the dynamic programming problem are computed backwards. ${ }^{27}$ In the inner loop, the moments are simulated conditional on the value functions. The presence of individual heterogeneity increases the state space and the value function is solved at every combination of worker's types. The standard errors are computed using the formula described in Appendix C.

For each individual in each sample period, we observe job mobility and employment choices and log wages if the individual is employed. The empirical moments include the means of job mobility, employment, transition from employment into unemployment, and log wages in each sample period, and the covariances of job mobility and log wage between any two sample periods. Since SIPP is a short panel, it is typical that some workers have left-censored life-cycle histories when they are observed in the first wave of SIPP. For these workers, their first observed wages are endogenous which leads to an initial condition problem (Heckman, 1981). The initial condition problem is solved by simulating the model starting from the beginning of life cycle and evaluating the moments conditional on each individual's first observed life-cycle period $\tau_{i} \cdot{ }^{28}$ The mean of elapsed job tenure when a worker is first observed in the sample is added to the set of moments to match. ${ }^{29}$ Details of the estimation procedure are discussed in Appendix C.

\section{$5 \quad$ Estimation Results}

Table 4-5 report estimates from the structural model for low-education men and high-education men, respectively. The first column contains estimates for the model with switching cost. Wage risk at the worker-firm match level is the dominating risk facing employed workers. For instance, among loweducation men, the variance of match-level shock $\left(\sigma_{\eta}^{2}\right)$ is $\frac{0.644}{100}$, whereas the variance of the person-level wage shocks is small and insignificant from zero $\left(\sigma_{\zeta}^{2}=\frac{0.009}{100}\right)$. Among high-education men, the variance of match-level shocks is even larger relative to the variance of individual-level shocks $\left(\frac{0.885}{100}\right.$ vs. $\left.\frac{0.002}{100}\right)$. These results imply that job mobility could be a very useful potential channel to react against a large fraction of permanent wage risk. The variance of the transitory shock is large. As noted previously,

\footnotetext{
${ }^{27}$ Appendix B describes the solution method to the value function in detail. The method uses Monte Carlo integration and an interpolation method to approximate the value function.

${ }^{28}$ Twenty simulations per individual are conducted. For each individual, the unobserved types are drawn from the type probability distributions at the beginning of each simulated path. The observations prior to period $\tau_{i}$ are discarded such that the distribution of $\tau_{i}$ in the simulated sample matches the distribution in the real data.

${ }^{29}$ Recall from Section 3.1 that the SIPP contains information on the starting date of worker's present job when he is first sampled. This information is used to construct the elapsed job tenure at the first interview date.
} 
transitory shocks represent a mix between a transitory shock and measurement error. ${ }^{30}$ It is potentially interesting to use external validation studies to separate out the contribution of true transitory shocks from measurement errors (Gottschalk, 2005; Abowd and Stinson, 2011). The canonical decomposition of shocks into transitory and permanent components is usually applied to annual earnings data where transitory shocks may well be important because of unemployment spells or temporary job spells. In the structural model, these sources of transitory shocks are modeled explicitly through employment and job mobility decisions. Therefore, I interpret that all estimated transitory shocks to wages represent measurement error.

The random growth factors are presented in ascending order by the individual's return to tenure (c). Among low-education men, while the unobserved return to tenure differs widely between the two types of individuals, only the return to tenure among type-2 individuals is significant (at $0.7 \%$ per period). The return to experience parameters among both types of individuals are small and imprecisely estimated. Among high-education men, random growth factors are generally small and insignificantly different from zero. Therefore, there is very limited support for heterogeneous return to tenure and heterogeneous return to experience. It is important to note that, even without any returns to experience and tenure, match-level wage shocks and job mobility alone can generate sufficient positive wage growth over time. This is because workers are able to preserve good match shocks and move away from bad match shocks by job mobility. The small estimates of return to tenure are in line with existing estimates after controlling for the endogeneity of job mobility. ${ }^{31}$ The estimated heterogeneity of the individual wage component at the start of life is larger than the initial match heterogeneity, particularly among low-education individuals. This has important implications to the sources of wage inequality discussed in the following section.

Table 6 reports the estimated switching cost parameters. The switching cost varies widely by type. Among low-education men, the high-cost individuals pay a utility cost equivalent to $7.8 \%$ of the periodwage in order to switch employers. The utility cost paid by the low-cost individuals is only $0.8 \%$ of the period-wage. Relative to low-education men, the utility cost of moving is high among the high-

\footnotetext{
${ }^{30}$ In our sample, measurement error in wages may come from two sources: from reported wages for those who are hourly paid, from reported earnings and/or hours for salary-paid workers.

${ }^{31}$ See Altonji and Williams (2005) for a reassessment of this literature. Most existing estimates (even after controlling for endogenous mobility) assume that any shock to match component is transitory and therefore does not relate to turnover behavior. Also, if return to tenure is heterogeneous, on-the-job search implies that workers whose returns are low tend to switch jobs at a faster rate, generating a positive relation to observed tenure. This is likely to produce a positive source of bias to existing estimators.
} 
educated. For instance, the type- 1 switching cost among high-education men is equivalent to $32 \%$ of the period-wage and, at the same time, the proportion of men belonging to the high-cost type is larger than low-education men. Interestingly, there is some weak evidence that marriage and house ownership are both negatively associated with the probability that the individual belongs to a high-cost type. The subsidy from spouses to job search activities could reduce the mobility costs of married workers. Young workers who own a house may be more likely to change jobs when there is a wage fall in order to make mortgage payments.

The identification of the full model hinges on exclusion restrictions. As a sensitivity test, I also estimate the model without switching cost, where job mobility is only influenced by wage differences. Columns (2) of Table 4-5 show that the estimated parameters are qualitatively similar. Relative to the estimates from the model with switching cost, the variance of match shocks becomes larger, particularly among high-education men whose switching costs are also large. Therefore, the model without switching costs over-estimates the extent of match-level risks. In addition to wages, unobserved non-wage factors play an important role in explaining individual's job mobility behavior.

What happens if shocks to the worker-firm match and job switching cost are ignored? This corresponds to the assumption made in Low, Meghir, and Pistaferri (2010) and Altonji, Smith, and Vidangos (2013), where the worker's mobility choice is solely based on the value of initial match. Columns (3) of Table 4-5 present the estimated parameters by holding the match values constant within jobs. Compared to columns (1) and (2), there is a large increase in the estimated variance of permanent shock (e.g. from $\frac{0.003}{100}$ to $\frac{0.051}{100}$ among high-education men). A large proportion of wage fluctuations that is in fact specific to a worker-firm match has been identified as permanent shocks which is assumed to persist across all jobs. In column (4), I estimate a canonical wage process by neglecting the matchspecific wage altogether and hence disallowing the worker's selection between jobs. This has been a standard in estimating wage uncertainty in the labor and macroeconomics literature. Compared to the estimated individual-level permanent shocks from the model taking job mobility into account (but assuming constant match) in column (3), the variance of permanent shocks becomes even larger. For instance, among low-education men, the canonical model implies that the variance of permanent shocks is $\frac{0.169}{100}$, compared to $\frac{0.05}{100}$ implied by the model with endogenous job mobility. These results are consistent with findings in Low, Meghir, and Pistaferri (2010), where they show, using a reduced-form model 
of job mobility, that over the half of the identified permanent wage uncertainty stems from worker's endogenous job mobility choice. ${ }^{32}$ Note that, the heterogeneity in individual wage growth $\left(\sigma_{\delta}^{2}\right)$ is very small and insignificant from zero even in the canonical model.

It is also useful to compare the true wage risk, corresponding to the wage risk prior to any job mobility decision, with the wage risk identified by canonical models where the firm-specific wage is neglected. In the structural model, the true wage risk is the sum of the variance of the person- and match-level shocks (abstracting from transitory shocks). Among low-education men, it is $\frac{0.644+0.009}{100}$ and, among high-education men, it is $\frac{0.885+0.002}{100}$. Among all individuals, the true wage risk more than three times as large as the variance of permanent shock identified from a canonical wage process (column 4).

Appendix Table A1 reports the fit of the model to the sample of low-education and high-education men, respectively. ${ }^{33}$ To evaluate the fit of the model, for each model specification, I simulate 20 careers for each worker in the sample. I then truncate the careers according to the individual's first observed life-cycle period $\tau_{i}$. The final simulated sample contains 8 observation periods, whose joint distribution of observables and $\tau_{i}$ matches the SIPP sample. For the estimated model in column (1) and (2), the simulated outcomes exhibit a reasonably good fit to the data. The simulations capture essential features of the data including the average wage, job mobility and employment, as well as the variance and autocovariance of wage and mobility. For the model without match-level shocks (column 3), the simulated outcomes show a reasonably good fit to the mean outcomes, but worse fit to outcomes involving higher-order moments. For instance, the predicted first-order autocovariances of mobility are small and close to zero, whereas the first-order covariances of mobility in the data are positive.

\footnotetext{
${ }^{32}$ In Low, Meghir and Pistaferri (2010), they assume that "the permanent shock occurs each quarter with probability 0.25. Thus, on average, the permanent component of wages changes once per year." (p. 1436). This implies that their variance of permanent shocks is larger than the estimates from the current paper, where permanent shocks to wages occur every four months.

${ }^{33}$ Due to space limits, the table only shows selected moments. The full predicted and actual moments are available upon request.
} 


\section{Implications of the Model}

\subsection{Value of Job Mobility in Response to Match-level Shocks}

To quantify the value of job mobility as a way of responding to the match-level wage shocks, I calculate the life-time expected utility of a worker holding the reservation wage fixed in every period at the level before match-level shock taken place in that period (thereby disallowing job mobility to respond to match-level shocks). Let $V_{0}^{e^{\prime}}\left(a_{i j 0}, u_{i 0}, \boldsymbol{\alpha}_{i}\right)$ be the value at the beginning of life in the counterfactual environment. Under the counterfactual, the dynamic programming problem is solved with respect to a modified conditional density function of the match component, $f^{\prime}\left(a_{i j t} \mid a_{i j t-1}, \eta_{i t}\right)$, where:

$$
f^{\prime}\left(a_{i j t} \mid a_{i j t-1}, \eta_{i t}\right)=g^{\prime}\left(a_{i j t} \mid M_{i t}, a_{i j t-1}, \eta_{i t}\right) h^{\prime}\left(M_{i t} \mid a_{i j t-1}, \eta_{i t}=0\right)
$$

where $\eta_{i t}$ is turned off in the $h^{\prime}$ density but not in the $g^{\prime}$ density. Conditioning on the worker's type and the match value at $t-1, h^{\prime}$ measures whether the worker would have moved in the absence of match-level shocks. Then, the value of job mobility at the beginning of life is given by

$$
\Delta V_{0}=V_{0}^{e}\left(a_{i j 0}, u_{i 0}, \boldsymbol{\alpha}_{i}\right)-V_{0}^{e^{\prime}}\left(a_{i j 0}, u_{i 0}, \boldsymbol{\alpha}_{i}\right)
$$

where $V_{0}^{e}\left(a_{i j 0}, u_{i 0}, \boldsymbol{\alpha}_{i}\right)$ is the life-time value allowing job mobility to respond to match-level shocks. $\Delta V_{0}$ measures the welfare value of job mobility in response to match-level risk. It depends on the model environment, in particular the extent of frictions in the labor market. For instance, when switching cost is large, job mobility is a less useful channel to act against negative match-level wage shocks. The higher the switching cost is, the closer is the $h^{\prime}\left(M_{i t} \mid a_{i j t-1}, \eta_{i t}=0\right)$ density from the $h\left(M_{i t} \mid a_{i j t-1}, \eta_{i t}\right)$ density and the smaller is the $\Delta V_{0}$.

Table 7 shows the calculated value of job mobility across different individual types and education groups. Panel A shows the welfare value of job mobility $\left(\Delta V_{0}\right)$ under the baseline environment (with switching cost). When represented as a percentage of the average life-time value a job $\left(V_{0}^{e}\right)$, the welfare gains of job mobility among high-education individuals range from 8-9\% for different types of workers. The value of job mobility is monotonically decreasing in the cost of job changes: workers whose switching cost is low have larger values of job mobility (both in absolute values and as a fraction 
of $V_{0}^{e}$ ) than those whose cost of switching employer is high. The value of job mobility is also slightly higher for workers of smaller random growth factors. Relative to high-education individuals, the welfare gain from job mobility for low-education individuals is much smaller overall. For instance, among loweducation individuals with low-switching cost and high random growth factors, the welfare value of job mobility only accounts for $4 \%$ of the life-time utility of employment, which is less than half of the value of high-education individuals of the same type.

In Panel $\mathrm{B}$, the value of job mobility is computed under a counterfactual environment where the variance of match-level shocks is reduced by half. Conditional on the individual's type, the value of job mobility is increasing in the variances of match-level shocks. When wage variations in the matchcomponent is high and switching cost is low, job mobility is a highly valuable channel to act against negative wage shocks. In Panel C, job offer arrival probability is reduced to half among the employed. Lower job arrival probability has large impact on the welfare value of job mobility. For instance, among high-education men whose switching cost is high and random growth factors are low, the value of job mobility is down to $5.5 \%$ of life-time utility, a $31 \%$ reduction relative to the baseline.

\subsection{Sources of Wage Growth and Inequality over Early Careers}

Using the estimated parameters (column (1) of Table 6), I simulate 20 paths from the beginning of life for each individual in the sample. I then decompose the mean and the variance of simulated population wages over the first 30 periods (10 years) of the life cycle. The primary interest is to evaluate the contribution from the match and the individual component to wages over time. The left panels of Figures 4-5 examine the age profile of mean wages, for low- and high-education men, respectively. While both the match component and individual component grow over time, the majority of log wage growth is driven by improved match values. The growth in $E\left(u_{t}\right)$ is due to the positive return to work experience. The growth in $E\left(a_{t}\right)$ is almost entirely due to job mobility, given the small (and even negative for some individual types) estimated mean return to tenure. Good shocks are preserved and bad shocks could be recovered through job changes. As the extent of job-to-job transitions decreases with potential experience, the growth of $E\left(a_{t}\right)$ gradually slows down, generating a concave experience profile of wages.

The right panels of Figures 4-5 decompose the age profile of wage inequality for young workers, 
for low- and high-education men, respectively. At the beginning of life, most wage inequality is from variation in individual heterogeneity (i.e. individual's general ability). As worker accumulates labor market experiences, the contribution from the worker-firm match quickly rises as a result of the permanent match shocks, job-to-job transitions, and heterogeneous return to tenure. For instance, among high-education men, after 10 years from the beginning of life, the contribution from match-level wages to overall log wage inequality exceeds that from the person-level wages. Therefore, it appears that differences in labor market histories are the main driving force behind the increasing inequality over life. This result is similar to recent findings from Huggett, Ventura, and Yaron (2011). It suggests that policies aiming at improving worker-firm matches are at least equally important as education policies aiming to improving initial conditions.

\subsection{Counterfactual Analysis: Implications of Risks}

Table 8 compares simulation results from five counterfactual scenarios for both low- and high-education men in the 30 th period (equivalent to the 10th year) of the dynamic model with switching costs. ${ }^{34}$ The baseline scenario (column 1) assumes that individuals are subject to match- and person-level wage risk and layoff risk which are estimated in the dynamic model with switching costs. In subsequent columns, the risk environment is modified as follows since the first period of the life-cycle, holding everything else constant at the baseline level: doubling the standard deviation of match-level shocks (column 2); doubling the standard deviation of match-level shocks and simultaneously doubling switching costs (column 3) or shutting down job mobility (column 4); doubling the standard deviation of individual-level shocks (column 5); doubling the layoff probability in each period (column 6). Results are separately reported for low-education men and high-education men.

Column 2 reports the effects of an increase in the variance of match-level shocks. Among low- and high-education men, the higher variance of match-level wage risk increases average log wage among workers, mainly as a result of improved match quality. The labor force participation rate remains the same as the baseline. The present discounted value (PDV) of utility also shows small increase, from 24.85 to 25.95 among low-education men and from 27.31 to 28.33 among high-education men. The welfare implications of match-level wage risk depend crucially on the degree of labor market frictions

\footnotetext{
${ }^{34}$ The results are based on 20 paths from the beginning of life for each individual in the sample, with unobserved types drawn from the discrete distribution.
} 
and the cost of job mobility. When the increase in match-level wage risk is accompanied by a rise in switching cost, the welfare gain declines (column 3). When job mobility is disallowed in the model (by setting offer arrival probability among employed workers to zero), an increase in the match-level wage risk reduces welfare relative to the baseline. For instance, among low-education men, the match component of wage declines by over $50 \%$ from 0.34 to 0.22 in period 30 , reducing the PDV of utility.

Columns 5-6 report the effects of an increase in the variance of individual-level shocks and the layoff probability, respectively. Doubling the variance of individual-level wage shocks barely changes individual's behavior and PDV of utility relative to the baseline. The standard deviation of individuallevel wage shocks appears to be too small to affect individual's behavior. Increasing the probability of a layoff reduces welfare, through reductions both in the average match component of wage among workers and in the fraction of individuals who are working.

\section{Conclusion}

I estimated a dynamic structural model of job mobility jointly with a stochastic wage process. In addition to decomposing wage shocks by their persistence, I also considered two sources of wage shocks, shocks at the worker-firm match level and shocks at the individual level which persist across jobs, and modeled their effects on dynamic individual behaviors. The estimation results suggest that wage risk at match level is the dominating type of risk facing employed individuals. I showed that job mobility is a valuable channel in response to the match-level wage shocks. The welfare value of job mobility depends critically on the magnitude of the job-switching costs and job offer arrival probability. I also identified the true wage risk prior to job mobility, which is almost three times as large as the wage risk estimated using observed wages alone.

The importance of match-level wage risk points to the significance of government programs aiming at improving worker-firm match quality and reducing frictions in the labor market. Given that the accumulated match-specific shocks account for much of the wage inequality for workers in their early careers, it suggests an important role for policy interventions (like job training programs) aiming to help workers recover from the loss of job-specific skills. For employed workers, recessions could lead to a rise in job switching cost or a decline in the offer arrival probability. Under either case, job mobility is less valuable in terms of its value in moving away from bad match-level shocks. Therefore, this paper 
suggests that the welfare of employed workers could also be greatly reduced in recessions. Decreasing activities of job-to-job transitions implies that match-level shocks would appear more persistent in recessions and thereby making the wage risk identified from observed wages larger. This coincides with empirical evidence from the literature finding that idiosyncratic risk is countercyclical. ${ }^{35}$

Recovering the true wage risk facing individuals from their choices is complex. While this paper takes a step to separate match-level risk from individual-level risk by modeling job mobility, it has several limitations that can be extended in future research. First, the modeling of job mobility decisions is simple and highly stylized. For instance, jobs could differ from each other in other aspects besides match quality. The switching cost parameter in this paper absorbs all the other non-wage factors affecting job mobility in a reduced-form way, but modeling transitions across jobs that differ explicitly in wage risk, return to tenure, or hours of work is desirable and left for future research. Each extension would add another state variable in the model and require a careful specification of the preference structure. Second, the variance of match-level shock is constant over time. If job quality is learnt over time, the variation of surprises to match quality is decreasing with job tenure as workers learn more about their match-specific productivity (Jovanovic, 1979). It would be interesting to explore the implication from a model where job is an "experience good". In that case, the option value of current job would be declining with tenure, which would presumably dampen the value of job mobility. Finally, an important avenue for future research is to analyze the relation between job mobility and other channels which workers can rely on in response to labor market risk, and to quantify their relative value in reacting against different types of shocks.

\footnotetext{
${ }^{35}$ See Storesletten, Telmer, and Yaron (2004).
} 


\section{APPENDIX}

\section{A Proof of Proposition 1}

In this section, the value function is conditional on worker's type $\boldsymbol{\alpha}_{i}$. I also assume that the individual wage component is nonstochastic and fixed at some value $u_{i}$. This simplifies notation (by avoiding to carry on $u_{i t}$ as a state variable) and does not change any of the implications concerning the properties of the reservation wage w.r.t to match value $a_{i j t}$.

Lemma 1. $V_{t}^{e}(a)$ is monotonically increasing its argument, for all $t$.

Proof. This can be established through backward induction.

$$
V_{T}^{e}\left(a_{i j T}\right)=a_{i j T}
$$

which is an increasing function in $a_{i j T}$ trivially. Now suppose $V_{t+1}^{e}\left(a_{i j t+1}\right)$ is increasing in $a_{i j t+1}$. Proving that $V_{t}^{e}\left(a_{i j t}\right)$ is increasing in $a_{i j t}$ concludes the induction. Now,

$$
\begin{aligned}
V_{t}^{e}\left(a_{i j t}\right) & =\ln w_{i j t}+\Gamma\left(1-\lambda^{e}\right)(1-\rho) E_{t} \max \left[V_{t+1}^{e}\left(a_{i j t+1}\right), V_{t+1}^{n}\right] \\
& +\Gamma \lambda^{e}(1-\rho) E_{t} \max \left[V_{t+1}^{e}\left(a_{i j t+1}\right), V_{t+1}^{e}\left(a_{i j^{\prime} t+1}\right)-k_{i}, V_{t+1}^{n}\right]+\rho \Gamma E\left(V_{t+1}^{n}\right)
\end{aligned}
$$

From Section 2, we know that

$$
\begin{aligned}
E_{t} \max \left[V_{t+1}^{e}\left(a_{i j t+1}\right), V_{t+1}^{n}\right]= & E_{t}\left[V_{t+1}^{e}\left(a_{i j t+1}\right)\right] \times P\left(a_{i j t+1} \geq g_{t+1} \mid a_{i j t}\right) \\
& +E_{t}\left[V_{t+1}^{n}\right] \times P\left(a_{i j t+1}<g_{t+1} \mid a_{i j t}\right)
\end{aligned}
$$

and

$$
E_{t}\left[V_{t+1}^{e}\left(a_{i j t+1}\right)\right]=\int V_{t+1}^{e}\left(a_{i j t+1}\right) d F\left(a_{i j t+1} \mid a_{i j t}\right)
$$

By the assumptions on the match process, it is easy to show that $F\left(a_{i j t+1} \mid a_{i j t}^{1}\right)$ first-order stochastically dominates $F\left(a_{i j t+1} \mid a_{i j t}^{2}\right)$, for any $a_{i j t}^{1}>a_{i j t}^{2}$. This implies that $\int v(k) d F\left(k \mid w^{1}\right)>\int v(k) d F\left(k \mid w^{2}\right)$ for any increasing function $v$. Since by assumption $V_{t+1}^{e}\left(a_{i j t+1}\right)$ is increasing in its argument and $a_{i j t+1}$ is increasing in $a_{i j t}, V_{t+1}^{e}\left(a_{i j t+1}\right)$ is also increasing in $a_{i j t}$. Hence we have established that $E_{t}\left[V_{t+1}^{e}\left(a_{i j t+1}\right)\right]$ is increasing in $a_{i j t}$. We can also show that $P\left(a_{i j t+1} \geq g_{t+1}\right)$ is increasing in $a_{i j t}$. Given that $V_{t+1}^{n}$ is independent of $a_{i j t}$, the continuation value when there is no external offer is increasing in $a_{i j t}$.

The argument for the monotonicity of the continuation value when there is a job offer is similar. Suppose the job offer is inferior to the job in period $t+1\left(V_{t+1}^{e}\left(a_{i j t+1}\right)>V_{t+1}^{e}\left(a_{i j^{\prime} t+1}\right)-k_{i}\right)$. Then, from equation (1), it is easy to show that $V_{t}^{e}\left(a_{i j t}\right)$ is increasing in its argument. Suppose the new job is superior to the current employer $\left(V_{t+1}^{e}\left(a_{i j t+1}\right)<V_{t+1}^{e}\left(a_{i j^{\prime} t+1}\right)-k_{i}\right)$. Since $a_{i j t+1}$ is increasing in $a_{i j t}$, $a_{i j^{\prime} t+1}$ must also be. Then $E_{t}\left[V_{t+1}^{e}\left(a_{i j^{\prime} t+1}\right)-k_{i}\right]$ is increasing in $a_{i j t}$ and hence $V_{t}^{e}\left(a_{i j t}\right)$ is increasing in its argument. 
Lemma 2. The reservation match value $h_{t}(a)$ is monotonically increasing in a, for all $t$.

Proof. The reservation match value satisfies:

$$
V_{t}^{e}\left(a_{i j t}\right)=V_{t}^{e}\left(h_{t}\left(a_{i j t}\right)\right)-k_{i}
$$

By the implicit function theorem ${ }^{36}$,

$$
\frac{\partial h_{t}\left(a_{i j t}\right)}{\partial a_{i j t}}=\frac{V_{t}^{e}\left(a_{i j t}\right)^{\prime}}{V_{t}^{e}\left(h_{t}\left(a_{i j t}\right)\right)^{\prime}}>0
$$

Lemma 3. $V_{t}^{e}(a)^{\prime}$ is monotonically increasing in a, for all $t=1 \ldots T-1$.

Proof. Assume that the value of unemployment is less than the value of employment in period $t+$ $1{ }^{37}$ Let $\Phi(\cdot)$ and $\phi(\cdot)$ denote cumulative and density function of the offer distribution respectively. Differentiating equation 1 w.r.t. $a_{i j t}$

$$
\begin{aligned}
\frac{\partial V_{t}^{e}\left(a_{i j t}\right)}{\partial a_{i j t}} & =1+\Gamma\left(1-\lambda^{e}\right) E_{t}\left(V_{t+1}^{e}\left(a_{i j t+1}\right)^{\prime}\right) \\
& +\Gamma \lambda^{e} E_{t}\left[V_{t+1}^{e}\left(a_{i j t+1}\right)^{\prime} \Phi\left(h_{t+1}\left(a_{i j t+1}\right)\right)+V_{t+1}^{e}\left(a_{i j t+1}\right) \phi\left(h_{t+1}\left(a_{i j t+1}\right)\right) \frac{\partial h_{t+1}\left(a_{i j t+1}\right)}{\partial a_{i j t+1}}\right] \\
& -\Gamma \lambda^{e} E_{t}\left[\left(V_{t+1}^{e}\left(h_{t+1}\left(a_{i j t+1}\right)\right)-k_{i}\right) \phi\left(h_{t+1}\left(a_{i j t+1}\right)\right) \frac{\partial h_{t+1}\left(a_{i j t+1}\right)}{\partial a_{i j t+1}}\right] \\
& =1+\Gamma\left(1-\lambda^{e}\right) E_{t}\left(V_{t+1}^{e}\left(a_{i j t+1}\right)^{\prime}\right)+\Gamma \lambda^{e} E_{t}\left[V_{t+1}^{e}\left(a_{i j t+1}\right)^{\prime} \Phi\left(h_{t+1}\left(a_{i j t+1}\right)\right)\right]
\end{aligned}
$$

where the last step follows because by definition, $V_{t+1}^{e}\left(h_{t+1}\left(a_{i j t+1}\right)\right)-k_{i}=V_{t+1}^{e}\left(a_{i j t+1}\right)$. From (3), we obtain

$$
\begin{aligned}
\frac{\partial^{2} V_{t}^{e}\left(a_{i j t}\right)}{\partial a_{i j t}^{2}} & =\Gamma\left(1-\lambda^{e}\right) E_{t}\left(\frac{\partial^{2} V_{t+1}^{e}\left(a_{i j t+1}\right)}{\partial a_{i j t+1}^{2}}\right) \\
& +\Gamma \lambda^{e} E_{t}\left[\frac{\partial^{2} V_{t+1}^{e}\left(a_{i j t+1}\right)}{\partial a_{i j t+1}^{2}} \Phi\left(h_{t+1}\left(a_{i j t+1}\right)+V_{t+1}^{e}\left(a_{i j t+1}\right)^{\prime} \phi\left(h_{t+1}\left(a_{i j t+1}\right)\right) \frac{\partial h_{t+1}\left(a_{i j t+1}\right)}{\partial a_{i j t+1}}\right]\right.
\end{aligned}
$$

From Lemma 1 and Lemma 2, we know the last term in equation (4) must be positive. In a backward induction argument, equation (4) essentially proves the core of the induction: if $\frac{\partial^{2} V_{t+1}^{e}\left(a_{i j t+1}\right)}{\partial a_{i j t+1}^{2}}$ is positive, then $\frac{\partial^{2} V_{t}^{e}\left(a_{i j t}\right)}{\partial a_{i j t}^{2}}$ must also be positive. Therefore, to complete the proof, we only need to show that the claim is true in the last period. In period $T, \frac{\partial^{2} V_{T}^{e}\left(a_{i j T}\right)}{\partial a_{i j T}^{2}}=0$. Moving one period backwards,

$$
V_{t}^{e}\left(a_{i j T-1}\right)=a_{i j T-1}+\Gamma\left(1-\lambda^{e}\right) E_{T-1}\left[a_{i j T}\right]+\Gamma \lambda^{e} E_{T-1}\left[\max a_{i j T}, a_{i j^{\prime} T}-k_{i}\right]
$$

\footnotetext{
${ }^{36} V(a)^{\prime}$ denotes partial derivative of the value function w.r.t $a$.

${ }^{37}$ In the case where unemployment is the optimal choice, $V_{t}^{e}(a)^{\prime}$ is independent of $a$.
} 
It is straightforward to show that $\frac{\partial^{2} V_{t}^{e}\left(a_{i j t}\right)}{\partial a_{i j t}^{2}}=\Gamma \lambda^{e} E_{T-1}\left(\phi\left(a_{i j T}+k_{i}\right)\right)>0$.

So far we have established that the worker's value function is monotonically increasing and convex. We are now ready to derive properties of the reservation wage in the presence of switching cost.

Proposition 1. For a worker of unobserved type $\boldsymbol{\alpha}_{i}$ with individual wage component $u_{i t}$, the reservation match for job mobility $\left(h_{t}\left(a_{i j t}\right)\right.$ satisfies the following properties for all $t=1 \ldots T-1$, :

(1) $h_{t}\left(a_{i j t}\right)>a_{i j t}$ if $k_{i}>0$ and $h_{t}\left(a_{i j t}\right)=a_{i j t}$ if $k_{i}=0$.

(2) $0<\frac{\partial h_{t}\left(a_{i j t}, k_{i}\right)}{\partial a_{i j t}}<1$.

Proof. With zero switching cost, the reservation match value satisfies:

$$
V_{t}^{e}\left(a_{i j t}\right)=V_{t}^{e}\left(h_{t}\left(a_{i j t}\right)\right)
$$

By Lemma 1, we conclude $h_{t}\left(a_{i j t}\right)=a_{i j t}$ for all $t$.

With positive switching cost, the reservation match value is defined by:

$$
V_{t}^{e}\left(a_{i j t}\right)=V_{t}^{e}\left(h_{t}\left(a_{i j t}\right)\right)-k_{i}
$$

Given $k_{i}>0$ and the value function is monotonically increasing, one can easily prove by contradiction that $h_{t}\left(a_{i j t}\right)>a_{i j t}$.

Finally, recall that $V_{t}^{e}(a)^{\prime}$ is positive (Lemma 1) and monotonically increasing (Lemma 3). Therefore,

$$
\begin{array}{r}
V_{t}^{e}\left(h_{t}\left(a_{i j t}\right)\right)^{\prime}>V_{t}^{e}\left(a_{i j t}\right)^{\prime}>0 \\
0<\frac{\partial h_{t}\left(a_{i j t}\right)}{\partial a_{i j t}}=\frac{V_{t}^{e}\left(a_{i j t}\right)^{\prime}}{V_{t}^{e}\left(h_{t}\left(a_{i j t}\right)\right)^{\prime}}<1
\end{array}
$$

\section{B Approximating the Value Function}

I choose to specify a terminal value function at time $T_{0}$ and solve the model backwards from $T_{0}$. The assumption at $t=T_{0}$ is that job mobility and employment decision cease and there are no match-level and individual-level wage shocks from $T_{0}+1$ until the end of work life $T$. I set $T=50$ periods and $T_{0}=35$ periods (one period corresponds to four months in the data).

The value function is solved at each combination of unobserved heterogeneity $\left(\boldsymbol{\alpha}_{i}\right)$. The computational burden from solving the value function arises primarily from the continuous and serially correlated state variables $u_{i t}$ and $a_{i j t}$. The difficulty is that, in order to evaluate value function at $t$, it is necessary to compute the value function for every possible value of $a_{i j t+1}$ and $u_{i t+1}$ which may arise in $t+1$. The number of possible values grow exponentially with $t$, making computation quickly infeasible. To circumvent this issue, I use an interpolation method developed in Bound, Stinebrickner, and 
Waidmann (2009). The method involves two steps. In the first step, I determine the range of possible values of $a_{i j t}$ and $u_{i t}$ which could arise from simulations used to approximate the value function and evaluate the moments in every period $t=1, \ldots, T_{0}$. In the second step, the value function is solved backwards. At each time $t$, the value function is evaluated at $N$ equally spaced grid point $a_{i j t}^{n}$ and $u_{i t}^{n}$. To calculate the value function at each grid point at time $t$, I need to calculate the value function at $t+1$ for possible values of $a_{i j t+1}$ and $u_{i t+1}$. These values will not correspond to the grid points in $t+1$ in general. At these points, the value function is evaluated by interpolation. For instance, each of the possible value functions at $a_{i j t+1}$ is approximated by interpolating between the two value functions associated with two surrounding grid points $a_{i j t+1}^{n-1}$ and $a_{i j t+1}^{n}$.

\section{Estimation by Method of Simulated Moments}

For any two sample periods $p_{1}$ and $p_{2}$ such that $1 \leq p_{1} \leq p_{2} \leq P$ (where $P$ denotes the last sample period), the vector of simulated moments is:

$$
\mathbf{g}\left(\theta ; p_{1}, p_{2}\right)=\mathbf{s}\left(p_{1}, p_{2}\right)-\frac{1}{N} \sum_{i=1}^{N} f\left(\theta ; \tau_{i}, p_{1}, p_{2}\right)
$$

where $N$ is the number of workers in the panel, $\mathbf{s}$ is a vector of empirical moments implied by the data, and $\frac{1}{N} \sum_{i=1}^{N} f\left(\theta ; \tau_{i}, p_{1}, p_{2}\right)$ is a vector of corresponding moments predicted by the model. ${ }^{38}$ The empirical moments include the following:

$$
\begin{aligned}
& E\left(M_{i p_{2}} \mid P_{i p_{2}}=1\right), E\left(\ln w_{i p_{2}} \mid P_{i p_{2}}=1\right), E\left(P_{i p_{2}}\right), E\left(P_{i p_{2}}=0 \mid P_{i, p_{2}-1}=1\right), \\
& \operatorname{cov}\left(\ln w_{i p_{1}}, \ln w_{i p_{2}} \mid P_{i p_{1}}=1, P_{i p_{2}}=1\right), \operatorname{cov}\left(M_{i p_{1}}, M_{i p_{2}} \mid P_{i p_{1}}=1, P_{i p_{2}}=1\right), \\
& \operatorname{cov}\left(\ln w_{i p_{1}}, M_{i p_{2}} \mid P_{i p_{1}}=1, P_{i p_{2}}=1\right), \operatorname{cov}\left(M_{i p_{1}}, \ln w_{i p_{2}} \mid P_{i p_{1}}=1, P_{i p_{2}}=1\right)
\end{aligned}
$$

The function $f$ cannot be computed analytically because, in the presence of endogenous selection on the match process, the distribution of the state variables at any given life period does not carry an analytical form. I choose to approximate it by its simulated counterpart:

$$
\hat{f}\left(\theta ; \tau_{i}, p_{1}, p_{2}\right)=\frac{1}{S} \sum_{s=1}^{S} f\left(\theta ; \hat{\nu_{s}}, \tau_{i}, p_{1}, p_{2}\right) \rightarrow f\left(\theta ; \tau_{i}, p_{1}, p_{2}\right)
$$

where $\left\{\hat{\nu}_{s}\right\}_{s=1}^{s=S}$ is a sequence of random variables that are identically and independently distributed. It consists of sequences of draws of job offers, shocks to match- and individual-specific component from the beginning of life-cycle, and a vector of person-specific unobserved heterogeneity $\boldsymbol{\alpha}_{i}$ drawn from the type probability distributions at the beginning of each simulated path. ${ }^{39}$ With $\hat{\nu}$, the model is able

\footnotetext{
${ }^{38}$ It is important to note that the predicted moment $f$ depends on $\tau_{i}$ (life-cycle period in the first sampling period). $\tau_{i}$, $p_{1}$ and $p_{2}$ map into two unique life periods $t_{1}$ and $t_{2}$.

${ }^{39}$ The normally distributed random variables are constructed through the inversion method. That is, first draw a vector of random variables $z$ from a uniform $(0,1)$ distribution. Evaluating the inverse of cumulative normal distribution $F^{-1}(z)$
} 
to simulate $S$ employment histories for each individual from the beginning of the life-cycle. Twenty simulations per individual are conducted. The observations prior to period $\tau_{i}$ are discarded such that the distribution of $\tau_{i}$ in the simulated sample matches the distribution in the real data. The mean of elapsed job tenure when a worker is first observed in the sample is added to the set of moments to match. The predicted moments are evaluated using simulated data containing $N \times S$ simulated paths, each of which spans $P$ periods.

Let $\mathbf{g}(\theta)$ be a vector consisting $\mathbf{g}\left(\theta ; p_{1}, p_{2}\right)$ at all possible combinations of $p_{1}$ and $p_{2}$. The size of vector $\mathbf{g}(\theta)$ is $M \times 1$. The goal of the MSM estimation is to find $\theta$ which minimizes:

$$
\mathbf{g}(\theta)^{\prime} \mathbf{g}(\theta)
$$

To obtain standard errors, define conformably the individual vector, $\boldsymbol{g}_{\boldsymbol{i}}$ and the corresponding residuals, $\boldsymbol{e}_{\boldsymbol{i}}=\boldsymbol{g}_{\boldsymbol{i}}-\mathbf{g}(\theta)$. The variance-covariance matrix of $\mathbf{g}(\theta)$ is $^{40}$ :

$$
V=\sum_{i=1}^{N}\left(\boldsymbol{e}_{\boldsymbol{i}} \boldsymbol{e}_{\boldsymbol{i}}^{\prime}\right)
$$

and the standard errors are given by

$$
\operatorname{var}(\widehat{\theta})=\left(G^{\prime} G\right)^{-1} G^{\prime} V G\left(G^{\prime} G\right)^{-1}
$$

where $G=\left.\frac{\partial f(\theta)}{\partial \theta}\right|_{\theta=\widehat{\theta}}$ is the Jacobian matrix evaluated at the estimated parameters $\widehat{\theta}^{41}$

yields a vector of normally distributed random variables. The uniform draws $z$ are held fixed and independent of model parameters. This guarantees that MSM objective function varies only with respect to changes in parameters of interest.

${ }^{40}$ Each individual in our data set contributes to only a subset of the moments (because, for example, wages and job mobility is only defined on workers). The notation in the equation below leaves it implicit.

${ }^{41}$ Also see Moffitt and Gottschalk (1995) and Blundell, Pistaferri, and Preston (2008) for a discussion about standard errors in this type of models. 


\section{References}

Abowd, J., AND D. CARD (1989): "On the covariance structure of earnings and hours changes," Econometrica, pp. 411-445.

Abowd, J. M., And M. H. Stinson (2011): "Estimating measurement error in SIPP annual job earnings: a comparison of Census Bureau survey and SSA administrative data," Discussion paper.

Altonji, J., And N. Williams (2005): "Do Wages Rise with Job Seniority? A Reassessment," Industrial and Labor Relations Review, 58(3), 370-397.

Altonji, J. G., A. A. Smith, And I. Vidangos (2013): "Modeling earnings dynamics," Econometrica, 81(4), 1395-1454.

Bagger, J., F. Fontaine, F. Postel-Vinay, and J. Robin (2011): "A Feasible Equilibrium Search Model of Individual Wage Dynamics with Experience Accumulation," in 2011 Meeting Papers, no. 278. Society for Economic Dynamics.

BAKer, M., And G. Solon (2003): "Earnings dynamics and inequality among Canadian men, 19761992: Evidence from longitudinal income tax records," Journal of Labor Economics, 21(2), 289-321.

Blundell, R., and L. Pistaferri (2003): "Income Volatility and Household Consumption: The Impact of Food Assistance Programs," The Journal of Human Resources, 38, 1032-1050.

Blundell, R., L. Pistaferri, and I. Preston (2008): "Consumption Inequality and Partial Insurance," American Economic Review, 98(5), 1887-1921.

Bound, J., T. Stinebrickner, and T. Waidmann (2009): "Health, economic resources and the work decisions of older men," Journal of Econometrics, forthcoming.

Burdett, K. (1978): "A theory of employee job search and quit rates," The American Economic Review, pp. 212-220.

Carroll, C. (1992): "The Buffer-Stock Theory of Saving: Some Macroeconomic Evidence," Brookings Papers on Economic Activity, 1992(2), 61-156.

Cunha, F., J. Heckman, and S. Navarro (2005): "Separating uncertainty from heterogeneity in life cycle earnings," Oxford Economic Papers, 57(2), 191.

Deaton, A. (1992): Understanding Consumption. Oxford University Press.

Flinn, C., And J. HeCKMAn (1982): "New methods for analysing structural models of labour force dynamics," Journal of Econometrics, 18, 115-168.

Gottschalk, P. (2005): "Downward nominal-wage flexibility: real or measurement error?," Review of Economics and Statistics, 87(3), 556-568. 
Gottschalk, P., and R. Moffitt (1994): "The Growth of Earnings Instability in the US Labor Market," Brookings Papers on Economic Activity, 1994(2), 217-272.

Gourinchas, P., and J. Parker (2002): "Consumption Over the Life Cycle," Econometrica, 70(1), $47-89$.

Gruber, J. (1997): "The consumption smoothing benefits of unemployment insurance," The American Economic Review, pp. 192-205.

Guvenen, F. (2007): "Learning your earning: Are labor income shocks really very persistent?," American Economic Review, 97(3), 687-712.

HAIDER, S. (2001): "Earnings instability and earnings inequality of males in the United States: 19671991," Journal of Labor Economics, 19(4), 799-836.

Heathcote, J., F. Perri, and G. L. Violante (2010): "Unequal we stand: An empirical analysis of economic inequality in the United States, 1967-2006," Review of Economic Dynamics, 13(1), 15-51.

Heathcote, J., K. Storesletten, and G. L. Violante (2009): "Quantitative Macroeconomics with Heterogeneous Households," Annual Review of Economics, 1(1), 319-354.

Heckman, J. (1981): "The incidental parameters problem and the problem of initial conditions in estimating a discrete time-discrete data stochastic process," Structural analysis of discrete data with econometric applications, pp. 179-195.

Heckman, J., And B. Singer (1984): "A method for minimizing the impact of distributional assumptions in econometric models for duration data," Econometrica, pp. 271-320.

Heckman, J. J., And B. E. Honore (1990): "The empirical content of the Roy model," Econometrica, pp. 1121-1149.

Hey, J., and C. MCKenna (1979): "To move or not to move?," Economica, 46(182), 175-185.

Huggett, M., G. Ventura, And A. Yaron (2011): "Sources of Lifetime Inequality," The American Economic Review, 101(7), 2923-54.

Jensen, S., And S. Shore (2008): "Changes in the Distribution of Income Volatility," working paper.

Jovanovic, B. (1979): "Job Matching and the Theory of Turnover," The Journal of Political Economy, $87(5), 972$.

KAPlan, G. (2012): "Moving back home: Insurance against labor market risk," Journal of Political Economy, 120(3), 446-512.

Lise, J., C. Meghir, and J. Robin (2012): "Matching, Sorting and Wages," Working Paper. 
Low, H. (2005): "Self-insurance in a life-cycle model of labour supply and savings," Review of Economic Dynamics, 8(4), 945-975.

Low, H., C. Meghir, and L. Pistaferri (2010): "Wage Risk and Employment Risk over the Life Cycle," The American Economic Review, 100(4), 1432-1467.

Low, H., And L. Pistaferri (2010): "Disability Risk, Disability Insurance and Life Cycle Behavior," working paper.

Meghir, C., And L. Pistaferri (2004): "Income Variance Dynamics and Heterogeneity," Econometrica, $72(1), 1-32$.

- (2011): "Earnings, Consumption and Life Cycle Choices," Handbook of Labor Economics, 4, $773-854$.

Moffitt, R., and P. Gottschalk (1995): "Trends in the Covariance Structure of Earnings in the U.S.: 1969-1987," working paper.

(2011): "Trends in the Transitory Variance of Male Earnings in the U.S, 1970-2004," NBER working paper.

Postel-Vinay, F., And H. Turon (2010): "On-the-Job Search, Productivity Shocks, and the Individual Earnings Process," International Economic Review, 51(3), 599-629.

Storesletten, K., C. Telmer, and A. Yaron (2004): "Cyclical dynamics in idiosyncratic labor market risk," Journal of Political Economy, 112(3), 695-717.

TOPEL, R., AND M. WARD (1992): "Job mobility and the careers of young men," The Quarterly Journal of Economics, pp. 439-479.

VAn Der Berg, G. (1992): "A structural dynamic analysis of job turnover and the costs associated with moving to another job," The Economic Journal, 102(414), 1116-1133.

Yamaguchi, S. (2010): "Job Search, Bargaining, and Wage Dynamics," Journal of Labor Economics, $28(3), 595-631$. 
Table 1: Summary Statistics, SIPP 1996

\begin{tabular}{rcc}
\hline Variable & Mean & $\begin{array}{c}\text { Standard } \\
\text { Deviation }\end{array}$ \\
& & \\
Demographics & & \\
Age & 27.40 & 2.46 \\
White & 0.72 & 0.45 \\
Some college or more & 0.55 & 0.50 \\
Metropolitan & 0.83 & 0.38 \\
Own a house & 0.49 & 0.50 \\
Married & 0.54 & 0.50 \\
Labor market variables & & \\
Wages & 11.62 & 5.35 \\
Hours of work per week & 42.11 & 11.32 \\
Elapsed job duration in the first observation period & 5.45 & 5.74 \\
Total number of observations & 13544 & \\
Proportion of job-job transition & 0.10 & 0.30 \\
\hline \hline
\end{tabular}

Note: Wages are deflated using monthly CPI-Urban (CPI=1 in 1996:1) and averaged over a four-month period (per wave).

Table 2: Total Number of Job Changes (in percentages), by Potential Experience

\begin{tabular}{rrrrrr}
\hline & \multicolumn{7}{c}{ Number of job changes } \\
& 0 & 1 & 2 & 3 & $4+$ \\
\hline Quartiles of initial & & & & & \\
life-cycle period & & & & & \\
Less than 25th (1-4) & 45.0 & 31.7 & 13.7 & 5.1 & 4.4 \\
$25-50(7-10)$ & 54.9 & 24.0 & 14.4 & 4.9 & 1.9 \\
$50-75(13-16)$ & 59.2 & 25.1 & 11.8 & 2.9 & 1.0 \\
More than 75th (19-22) & 69.2 & 20.2 & 8.2 & 2.4 & 0.0 \\
& & & & & \\
Total & 56.4 & 25.6 & 12.2 & 3.9 & 1.95 \\
\hline \hline
\end{tabular}


Table 3: Job Mobility on Past Wage Changes

\begin{tabular}{rccccc}
\hline & $(1)$ & $(2)$ & $(3)$ & $(4)$ & $(5)$ \\
\hline Wthin job wage growth in $t-1$ & $-0.035^{* * *}$ & $-0.039^{* * *}$ & $-0.068^{* * *}$ & $-0.105^{* * *}$ & $-0.083^{* * *}$ \\
& $(0.013)$ & $(0.013)$ & $(0.014)$ & $(0.018)$ & $(0.021)$ \\
Within job wage growth in $t-2$ & - & - & - & & $-0.124^{* * *}$ \\
& & & & & $(0.030)$ \\
Job tenure in $t-1$ & - & $-0.005^{* * *}$ & $-0.004^{* * *}$ & $0.047^{* * *}$ & $0.072^{* * *}$ \\
& & $(0.000)$ & $(0.000)$ & $(0.003)$ & $(0.006)$ \\
$\ln \left(w_{t-2}\right)$ & - & - & $-0.060^{* * *}$ & $-0.151^{* * *}$ & - \\
$\ln \left(w_{t-3}\right)$ & - & - & $(0.008)$ & $(0.026)$ & \\
& & - & - & & $-0.171^{* * *}$ \\
Experience in $t-1$ & - & - & -0.001 & $-0.026^{* * *}$ & $-0.042^{* * *}$ \\
& & & $(0.001)$ & $(0.003)$ & $(0.006)$ \\
Individual FE & No & No & No & Yes & Yes \\
Observations & 8638 & 8638 & 8638 & 8638 & 6513 \\
\hline \hline
\end{tabular}

Note: $* * * p<0.01,{ }^{* *} p<0.05,{ }^{*} p<0.1$. The dependent variable is a job change indicator in period $t$ (equals to one if a job change occurs). The model is estimated by OLS. Standard errors (in parenthesis) are clustered by person. 
Table 4: Estimated Model Parameters-Low Education Men

\begin{tabular}{|c|c|c|c|c|}
\hline & $\begin{array}{c}\text { With Job- } \\
\text { switching Cost }\end{array}$ & $\begin{array}{c}\text { No Job- } \\
\text { switching Cost }\end{array}$ & $\begin{array}{l}\text { No Match- } \\
\text { level Shocks }\end{array}$ & $\begin{array}{c}\text { No Match- } \\
\text { specific Wages }\end{array}$ \\
\hline & (1) & $(2)$ & $(3)$ & $(4)$ \\
\hline \multicolumn{5}{|l|}{ Wage shocks } \\
\hline$\sigma_{\eta}^{2} \times 100$ & $\begin{array}{c}0.644 \\
(0.204)\end{array}$ & $\begin{array}{c}0.709 \\
(0.213)\end{array}$ & - & - \\
\hline$\sigma_{\zeta}^{2} \times 100$ & 0.009 & 0.008 & 0.050 & 0.169 \\
\hline & $(0.652)$ & $(0.596)$ & $(0.019)$ & $(0.078)$ \\
\hline$\sigma_{v}^{2}$ & 0.032 & 0.035 & 0.017 & 0.036 \\
\hline & $(0.009)$ & $(0.009)$ & $(0.005)$ & $(0.002)$ \\
\hline \multicolumn{5}{|l|}{ Random growth factors } \\
\hline$c_{1}$ & $\begin{array}{c}0.001 \\
(0.011)\end{array}$ & $\begin{array}{l}-0.004 \\
(0.596)\end{array}$ & - & - \\
\hline$c_{2}$ & $\begin{array}{c}0.007 \\
(0.003)\end{array}$ & $\begin{array}{c}0.006 \\
(0.002)\end{array}$ & - & - \\
\hline$\delta_{1}$ & 0.000 & -0.001 & 0.007 & - \\
\hline & $(0.101)$ & $(0.565)$ & $(0.003)$ & \\
\hline$\delta_{2}$ & 0.001 & 0.002 & 0.005 & - \\
\hline & $(0.024)$ & $(0.027)$ & $(0.014)$ & \\
\hline \multirow{2}{*}{ Fraction of type- 2 individuals } & 0.835 & 0.955 & 0.540 & - \\
\hline & $(0.778)$ & $(0.087)$ & $(4.836)$ & \\
\hline$\sigma_{\delta}^{2} \times 10^{5}$ & - & - & - & $\begin{array}{c}0.000 \\
(0.002)\end{array}$ \\
\hline \multicolumn{5}{|l|}{ Heterogeneity } \\
\hline$\sigma_{a_{0}}^{2}$ & $\begin{array}{c}0.003 \\
(0.001)\end{array}$ & $\begin{array}{c}0.002 \\
(0.000)\end{array}$ & $\begin{array}{c}0.024 \\
(0.010)\end{array}$ & - \\
\hline \multirow[t]{2}{*}{$\sigma_{u_{0}}^{2}$} & 0.060 & 0.055 & 0.091 & 0.076 \\
\hline & $(0.076)$ & $(0.068)$ & $(0.040)$ & $(0.009)$ \\
\hline \multicolumn{5}{|l|}{ Other parameters } \\
\hline \multirow[t]{2}{*}{$\beta_{0}$} & 2.017 & 2.013 & 1.999 & - \\
\hline & $(0.030)$ & $(0.033)$ & $(0.050)$ & \\
\hline \multirow[t]{2}{*}{$\alpha_{1}$} & 0.239 & 0.166 & 0.558 & - \\
\hline & - & - & $(0.155)$ & \\
\hline \multirow[t]{2}{*}{$\lambda^{e}$} & 0.604 & 0.444 & 0.179 & - \\
\hline & $(0.038)$ & $(0.038)$ & $(0.034)$ & \\
\hline \multirow[t]{2}{*}{$\lambda^{n}$} & 0.807 & 0.807 & 0.941 & - \\
\hline & $(0.017)$ & $(0.015)$ & $(0.182)$ & \\
\hline \multirow[t]{2}{*}{$\rho$} & 0.016 & 0.016 & 0.016 & - \\
\hline & $(0.000)$ & $(0.000)$ & $(0.002)$ & \\
\hline
\end{tabular}

Note: Standard errors are in parentheses. $\sigma_{\eta}^{2}, \sigma_{\zeta}^{2}$ and $\sigma_{v}^{2}$ are, respectively, the variances of match- and person-level shocks, and transitory shocks (including measurement error). $c$ and $\delta$ are the random growth factors at match- and person-level, respectively. $\sigma_{a_{0}}^{2}$ is the heterogeneity in the offered match values. $\sigma_{u_{0}}^{2}$ is the heterogeneity in the person-component of wages at the start of work life. $\lambda^{e}$ and $\lambda^{n}$ are the offer arrival probabilities during employment and unemployment, respectively. $\rho$ is the layoff probability. $\beta_{0}$ is the constant term in the offered log wage equation. $\alpha_{1}$ is the preference for not working. 
Table 5: Estimated Model Parameters-High Education Men

\begin{tabular}{|c|c|c|c|c|}
\hline & $\begin{array}{c}\text { With Job- } \\
\text { switching Cost }\end{array}$ & $\begin{array}{c}\text { No Job- } \\
\text { switching Cost }\end{array}$ & $\begin{array}{l}\text { No Match- } \\
\text { level Shocks }\end{array}$ & $\begin{array}{c}\text { No Match- } \\
\text { specific Wages }\end{array}$ \\
\hline & (1) & $(2)$ & $(3)$ & (4) \\
\hline \multicolumn{5}{|l|}{ Wage shocks } \\
\hline$\sigma_{\eta}^{2} \times 100$ & $\begin{array}{c}0.885 \\
(0.358)\end{array}$ & $\begin{array}{c}1.169 \\
(0.457)\end{array}$ & - & - \\
\hline$\sigma_{\zeta}^{2} \times 100$ & 0.002 & 0.003 & 0.051 & 0.279 \\
\hline & $(0.000)$ & $(0.001)$ & $(0.001)$ & $(0.083)$ \\
\hline$\sigma_{v}^{2}$ & 0.039 & 0.041 & 0.045 & 0.053 \\
\hline & $(0.006)$ & $(0.010)$ & $(0.010)$ & $(0.002)$ \\
\hline \multicolumn{5}{|l|}{ Random growth factors } \\
\hline$c_{1}$ & $\begin{array}{l}-0.005 \\
(0.003)\end{array}$ & $\begin{array}{l}-0.009 \\
(0.018)\end{array}$ & - & - \\
\hline$c_{2}$ & $\begin{array}{c}0.002 \\
(0.111)\end{array}$ & $\begin{array}{c}0.001 \\
(0.016)\end{array}$ & - & - \\
\hline$\delta_{1}$ & $\begin{array}{c}0.004 \\
(0.015)\end{array}$ & $\begin{array}{c}0.007 \\
(0.003)\end{array}$ & $\begin{array}{l}-0.002 \\
(0.003)\end{array}$ & - \\
\hline$\delta_{2}$ & $\begin{array}{c}0.005 \\
(0.272)\end{array}$ & $\begin{array}{c}0.006 \\
(0.049)\end{array}$ & $\begin{array}{c}0.004 \\
(0.049)\end{array}$ & - \\
\hline Fraction of type-2 individuals & $\begin{array}{c}0.068 \\
(0.388)\end{array}$ & $\begin{array}{c}0.199 \\
(0.102)\end{array}$ & $\begin{array}{c}0.564 \\
(0.102)\end{array}$ & - \\
\hline$\sigma_{\delta}^{2} \times 10^{5}$ & - & - & - & $\begin{array}{c}0.000 \\
(0.012)\end{array}$ \\
\hline \multicolumn{5}{|l|}{ Heterogeneity } \\
\hline$\sigma_{a_{0}}^{2}$ & $\begin{array}{c}0.046 \\
(0.015)\end{array}$ & $\begin{array}{c}0.031 \\
(0.000)\end{array}$ & $\begin{array}{c}0.172 \\
(0.000)\end{array}$ & - \\
\hline$\sigma_{u_{0}}^{2}$ & $\begin{array}{c}0.076 \\
(0.094)\end{array}$ & $\begin{array}{c}0.037 \\
(0.074)\end{array}$ & $\begin{array}{c}0.046 \\
(0.074)\end{array}$ & $\begin{array}{c}0.085 \\
(0.012)\end{array}$ \\
\hline \multicolumn{5}{|l|}{ Other parameters } \\
\hline$\beta_{0}$ & $\begin{array}{c}2.121 \\
(0.058)\end{array}$ & $\begin{array}{c}2.184 \\
(0.042)\end{array}$ & $\begin{array}{c}2.058 \\
(0.120)\end{array}$ & - \\
\hline$\alpha_{1}$ & $\begin{array}{c}0.631 \\
-\end{array}$ & $\begin{array}{c}0.284 \\
-\end{array}$ & $\begin{array}{c}0.073 \\
(0.141)\end{array}$ & - \\
\hline$\lambda^{e}$ & $\begin{array}{c}0.613 \\
(0.087)\end{array}$ & $\begin{array}{c}0.281 \\
(0.022)\end{array}$ & $\begin{array}{c}0.240 \\
(0.022)\end{array}$ & - \\
\hline$\lambda^{n}$ & $\begin{array}{c}0.701 \\
(0.019)\end{array}$ & $\begin{array}{c}0.586 \\
(0.012)\end{array}$ & $\begin{array}{c}0.617 \\
(0.012)\end{array}$ & - \\
\hline$\rho$ & $\begin{array}{c}0.004 \\
(0.000)\end{array}$ & $\begin{array}{c}0.002 \\
(0.000)\end{array}$ & $\begin{array}{c}0.000 \\
(0.000)\end{array}$ & - \\
\hline
\end{tabular}

Note: Standard errors are in parentheses. $\sigma_{\eta}^{2}, \sigma_{\zeta}^{2}$ and $\sigma_{v}^{2}$ are, respectively, the variances of match- and person-level shocks, and transitory shocks (including measurement error). $c$ and $\delta$ are the random growth factors at match- and person-level, respectively. $\sigma_{a_{0}}^{2}$ is the heterogeneity in the offered match values. $\sigma_{u_{0}}^{2}$ is the heterogeneity in the person-component of wages at the start of work life. $\lambda^{e}$ and $\lambda^{n}$ are the offer arrival probabilities during employment and unemployment, respectively. $\rho$ is the layoff probability. $\beta_{0}$ is the constant term in the offered log wage equation. $\alpha_{1}$ is the preference for not working. 
Table 6: Estimated Model Parameters-Switching Costs Parameters

\begin{tabular}{rcc}
\hline & Low education & High education \\
\hline$k_{1}$ & 0.078 & 0.320 \\
& $(0.045)$ & $(0.178)$ \\
$k_{2}$ & 0.008 & 0.163 \\
& $(0.006)$ & $(0.246)$ \\
$\gamma_{0}$ (constant) & -2.533 & -3.029 \\
& $(0.814)$ & $(1.015)$ \\
$\gamma_{1}$ (married) & 2.388 & 1.174 \\
$\gamma_{2}$ (house ownership) & $(1.094)$ & $(2.021)$ \\
& 0.510 & 1.541 \\
\hline \hline
\end{tabular}

Note: Standard errors are in parentheses.

Table 7: Value of Job Mobility in Response to Match-level Wage Shocks

\begin{tabular}{ccccc}
\hline & \multicolumn{2}{c}{ High education } & \multicolumn{2}{c}{ Low education } \\
Individual type & $\Delta V_{0}$ & $\frac{\Delta V_{0}}{V_{0}}$ & $\Delta V_{0}$ & $\frac{\Delta V_{0}}{V_{0}}$ \\
\hline Panel A: Baseline & & & \\
High switching cost-low random growth & 2.576 & 0.084 & 0.974 & 0.036 \\
High switching cost-high random growth & 2.502 & 0.080 & 0.918 & 0.033 \\
Low switching cost-low random growth & 2.801 & 0.091 & 1.151 & 0.042 \\
Low switching cost-high random growth & 2.713 & 0.086 & 1.091 & 0.040 \\
Panel B: Variance of match-level shocks $\times 0.5$ \\
High switching cost-low random growth & 2.396 & 0.080 & 0.834 & 0.032 \\
High switching cost-high random growth & 2.294 & 0.075 & 0.790 & 0.029 \\
Low switching cost-low random growth & 2.613 & 0.087 & 0.982 & 0.037 \\
Low switching cost-high random growth & 2.493 & 0.081 & 0.928 & 0.034 \\
Panel C: Job offer arrival rate & (among & employed) & $\times 0.5$ & \\
High switching cost-low random growth & 1.638 & 0.055 & 0.598 & 0.023 \\
High switching cost-high random growth & 1.593 & 0.052 & 0.565 & 0.021 \\
Low switching cost-low random growth & 1.787 & 0.060 & 0.696 & 0.026 \\
Low switching cost-high random growth & 1.733 & 0.057 & 0.658 & 0.024 \\
\hline \hline
\end{tabular}


Table 8: Counterfactual Analysis: Implications of Risk, Period 30 (Year 10)

\begin{tabular}{rcccccc}
\hline & \multicolumn{7}{c}{ Incr. match risk $\left(\sigma_{\eta} \times 2\right)$} \\
& Basline & JM & $\mathrm{SC} \times 2$ & No JM & $\sigma_{\zeta} \times 2$ & $\rho \times 2$ \\
& $(1)$ & $(2)$ & $(3)$ & $(4)$ & $(5)$ & $(6)$ \\
\hline Low-education men & & & & & & \\
Work (\%) & 97.83 & 97.83 & 97.83 & 98.24 & 97.83 & 96.21 \\
Job mobility (\%) & 6.11 & 7.26 & 7.05 & 0.00 & 6.11 & 8.16 \\
Log wage & 2.38 & 2.61 & 2.61 & 2.26 & 2.38 & 2.32 \\
Individual component & 2.04 & 2.04 & 2.04 & 2.04 & 2.04 & 2.04 \\
Match component & 0.34 & 0.57 & 0.57 & 0.22 & 0.34 & 0.28 \\
PDV utility & 24.85 & 25.95 & 25.86 & 23.97 & 24.85 & 24.30 \\
High-education men & & & & & & \\
Work (\%) & 99.40 & 99.40 & 99.40 & 99.42 & 99.40 & 99.10 \\
Job mobility (\%) & 5.10 & 6.47 & 5.96 & 0.00 & 5.10 & 6.57 \\
Log wage & 2.70 & 2.98 & 2.97 & 2.71 & 2.70 & 2.69 \\
Individual component & 2.26 & 2.26 & 2.26 & 2.26 & 2.26 & 2.26 \\
Match component & 0.44 & 0.71 & 0.71 & 0.46 & 0.44 & 0.43 \\
PDV utility & 27.31 & 28.33 & 27.96 & 26.12 & 27.31 & 27.15 \\
\hline \hline
\end{tabular}

Note: column (1): baseline; column (2): increase in the variance of match-level shocks $\left(\sigma_{\eta} \times 2\right)$, holding the rest of parameters under the baseline; column (3): $\sigma_{\eta} \times 2$ together with doubling switching costs; column (4): $\sigma_{\eta} \times 2$ together with zero offer arrival probability when employed; column (4): increase in the variance of individual-level shocks; column (5): increase in the layoff probability. 
Figure 1: Distributions of Within- and Between-job Log Wage Changes
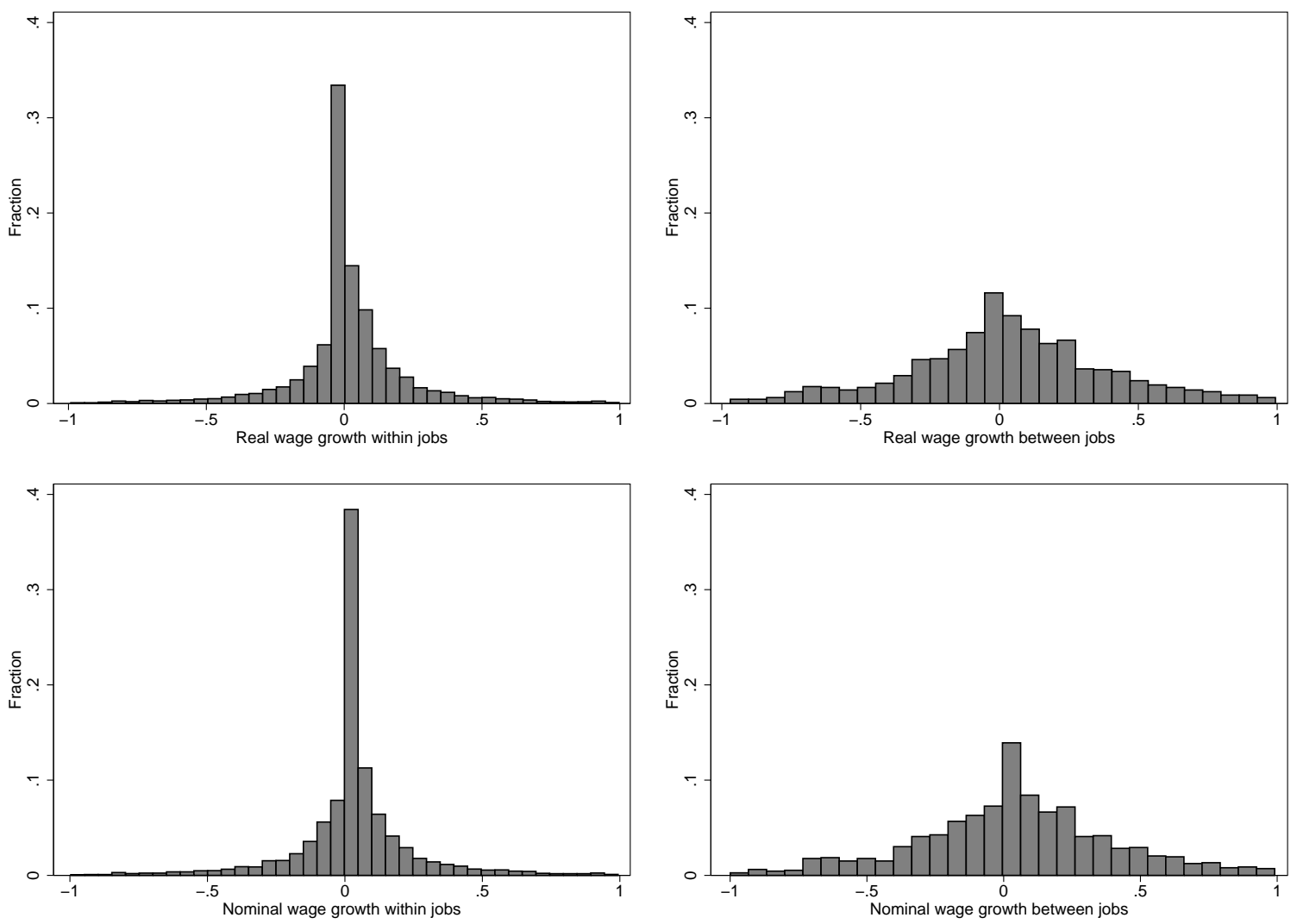

Note: The top two figures show the distribution of real log wage growth between waves within (left) and between jobs (right). The means (standard deviations) are 0.018(0.24) and 0.052(0.45), respectively. The bottom two figures show the distribution of nominal log wage growth between waves within (left) and between jobs (right). The means (standard deviations) are 0.024(0.24) and 0.059(0.45), respectively. 
Figure 2: Match-specific Wages and Job Mobility
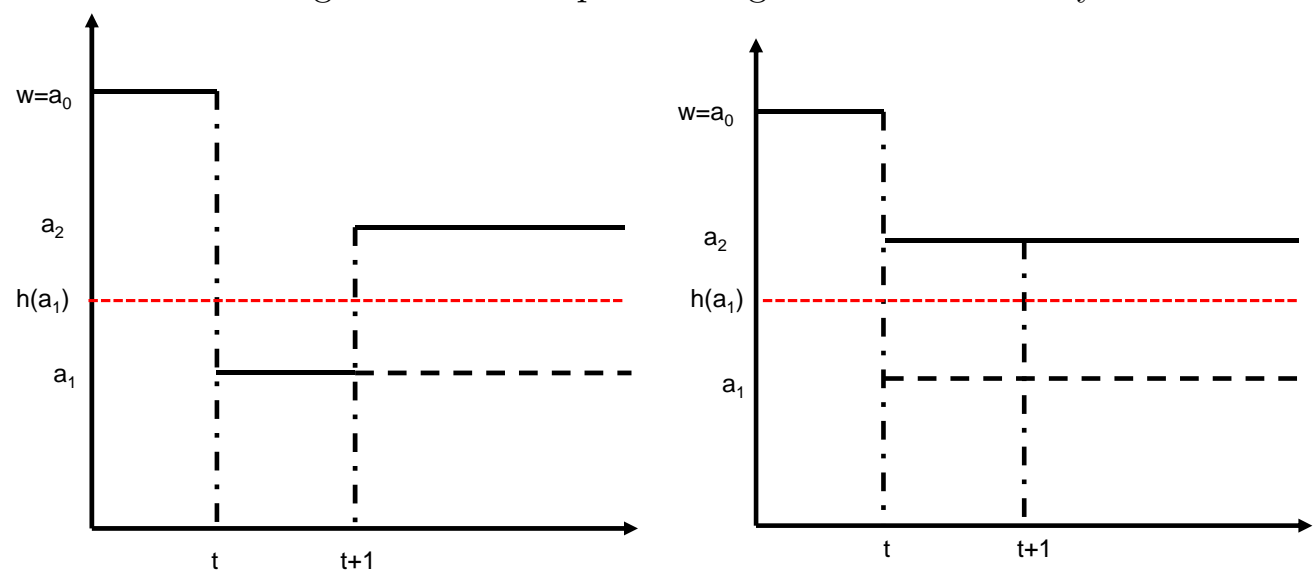

Figure 3: The Effect of $\sigma_{\eta}^{2}$ and $\sigma_{c}^{2}$ on the Autocovariance of Job Mobility Over Time
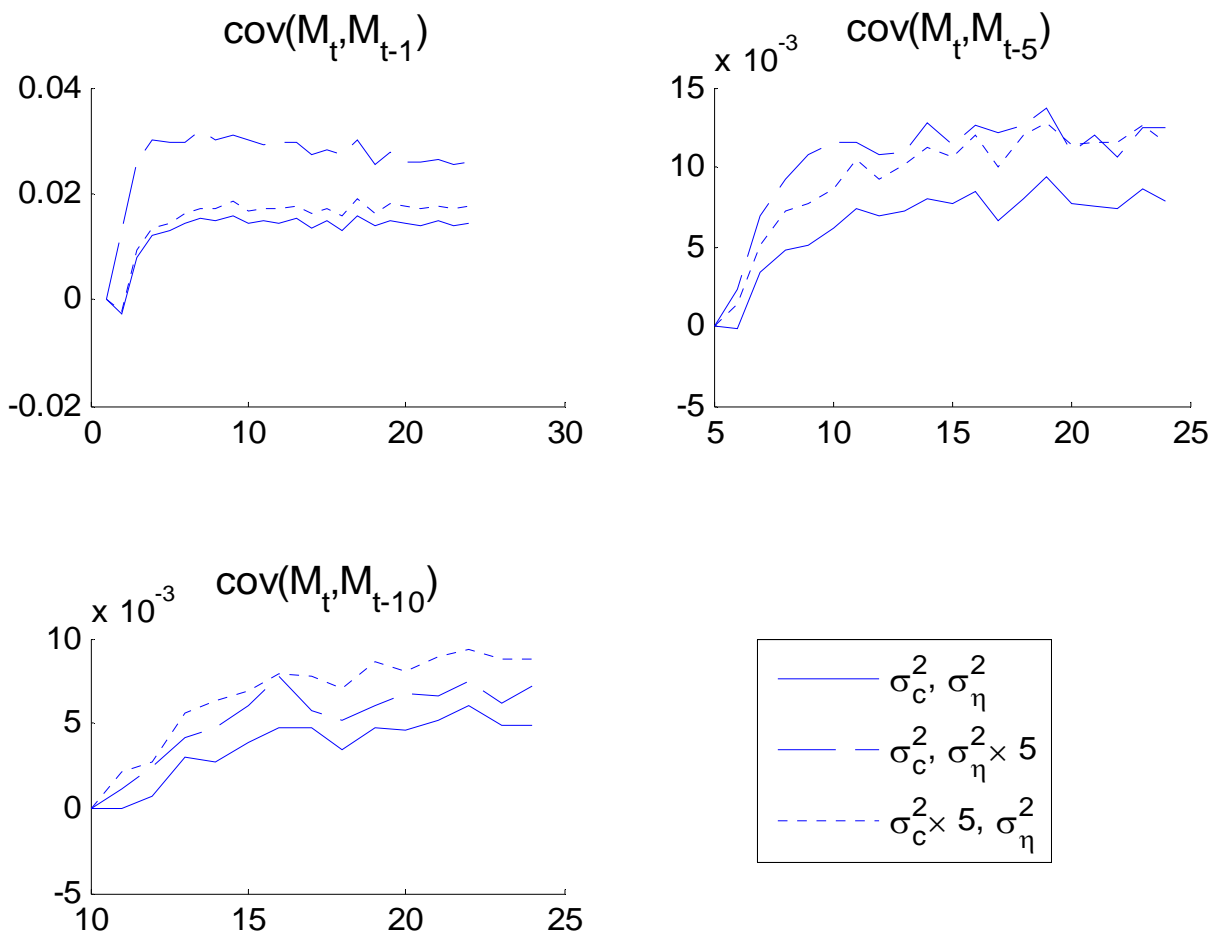

Note: Simulated from the model without switching cost. Baseline: $\sigma_{c}^{2}=4.96 \times 10^{-4}, \sigma_{\eta}^{2}=0.0062$ 
Figure 4: Decomposing the Experience-Profile of Log Wages and Variances of Log Wages: Loweducation Men
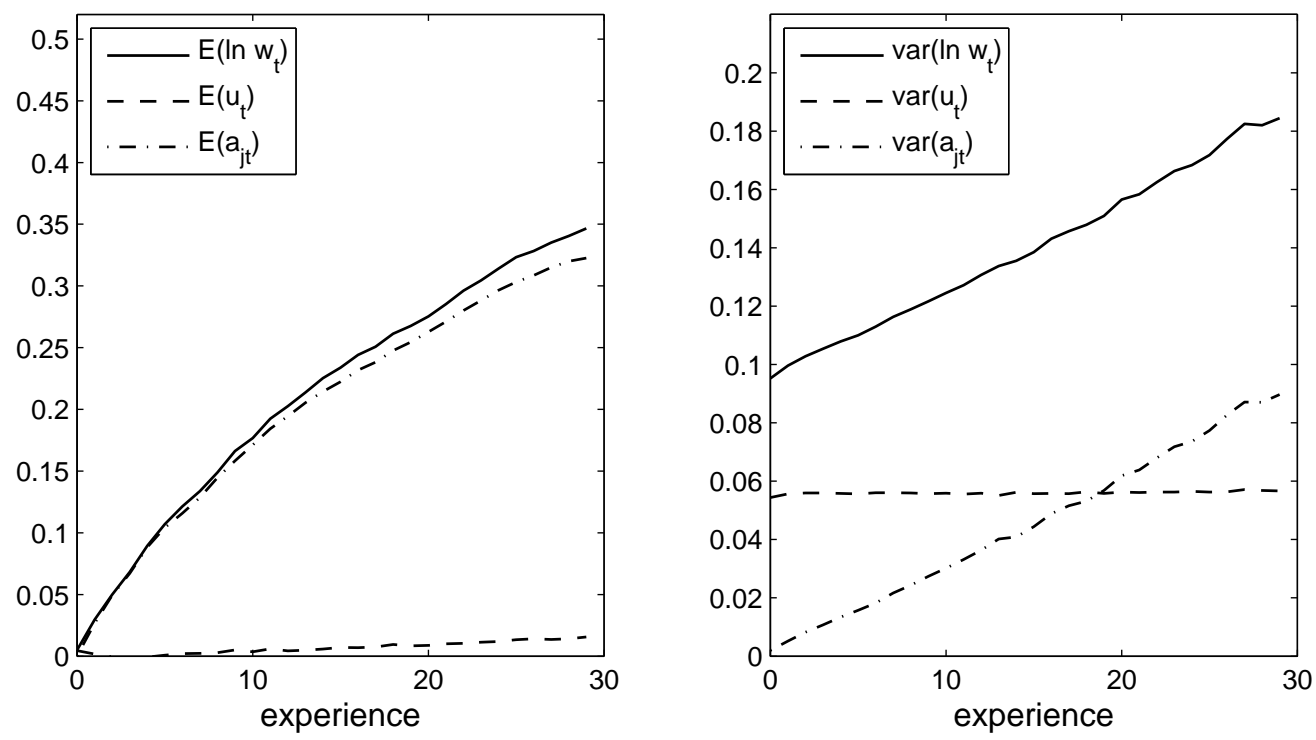

Figure 5: Decomposing the Experience-Profile of Log Wages and Variances of Log Wages: Higheducation Men
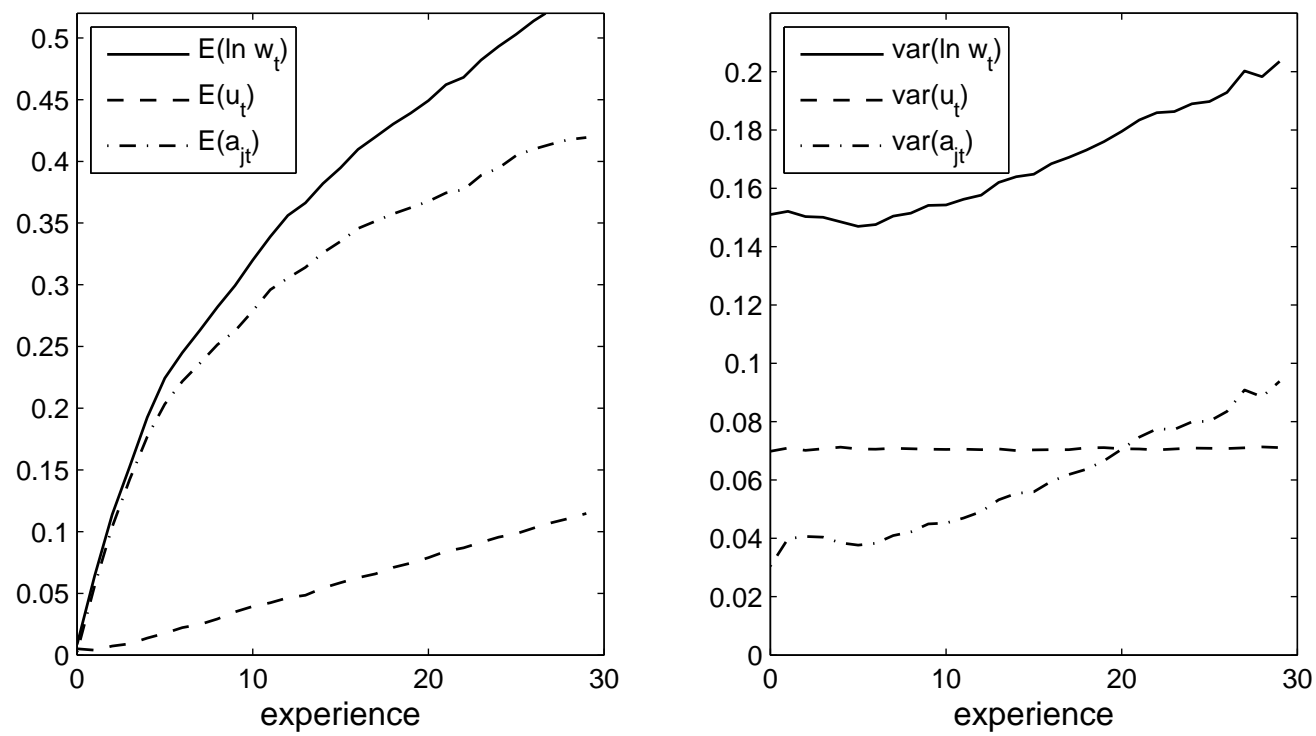
Table A1: Goodness of Fit (Selected Moments)

\begin{tabular}{|c|c|c|c|c|c|c|c|c|}
\hline \multirow[b]{2}{*}{ Moment } & \multicolumn{4}{|c|}{ Low-education } & \multicolumn{4}{|c|}{ High-education } \\
\hline & Data & Baseline & No SC & Con. match & Data & Baseline & No SC & Con. match \\
\hline \multirow{8}{*}{$\begin{array}{l}\text { Mean log } \\
\text { wage } \\
\text { (period 1-8) }\end{array}$} & 2.150 & 2.169 & 2.163 & 2.163 & 2.401 & 2.424 & 2.426 & 2.417 \\
\hline & 2.169 & 2.179 & 2.175 & 2.183 & 2.419 & 2.438 & 2.435 & 2.440 \\
\hline & 2.180 & 2.190 & 2.189 & 2.194 & 2.438 & 2.457 & 2.453 & 2.457 \\
\hline & 2.193 & 2.205 & 2.201 & 2.206 & 2.466 & 2.474 & 2.468 & 2.470 \\
\hline & 2.223 & 2.216 & 2.216 & 2.216 & 2.496 & 2.490 & 2.485 & 2.484 \\
\hline & 2.233 & 2.228 & 2.228 & 2.227 & 2.508 & 2.506 & 2.504 & 2.501 \\
\hline & 2.254 & 2.241 & 2.240 & 2.234 & 2.538 & 2.519 & 2.520 & 2.513 \\
\hline & 2.270 & 2.249 & 2.253 & 2.244 & 2.572 & 2.531 & 2.534 & 2.525 \\
\hline \multirow{8}{*}{$\begin{array}{l}\text { Prob. Of job } \\
\text { mobility } \\
\text { (period 1-8) }\end{array}$} & 0.000 & 0.000 & 0.000 & 0.000 & 0.000 & 0.000 & 0.000 & 0.000 \\
\hline & 0.128 & 0.124 & 0.121 & 0.061 & 0.103 & 0.097 & 0.087 & 0.082 \\
\hline & 0.119 & 0.119 & 0.113 & 0.050 & 0.113 & 0.097 & 0.098 & 0.077 \\
\hline & 0.110 & 0.106 & 0.099 & 0.056 & 0.110 & 0.086 & 0.090 & 0.075 \\
\hline & 0.110 & 0.099 & 0.099 & 0.055 & 0.087 & 0.083 & 0.077 & 0.075 \\
\hline & 0.091 & 0.090 & 0.091 & 0.046 & 0.103 & 0.084 & 0.094 & 0.071 \\
\hline & 0.098 & 0.092 & 0.083 & 0.059 & 0.098 & 0.069 & 0.079 & 0.066 \\
\hline & 0.099 & 0.084 & 0.090 & 0.056 & 0.083 & 0.070 & 0.070 & 0.067 \\
\hline \multirow{8}{*}{$\begin{array}{l}\text { Prob. Of } \\
\text { employment } \\
\text { (period 1-8) }\end{array}$} & 0.938 & 0.945 & 0.943 & 0.944 & 0.979 & 0.956 & 0.945 & 0.942 \\
\hline & 0.952 & 0.975 & 0.974 & 0.892 & 0.982 & 0.984 & 0.975 & 0.960 \\
\hline & 0.948 & 0.984 & 0.980 & 0.926 & 0.983 & 0.991 & 0.990 & 0.972 \\
\hline & 0.959 & 0.980 & 0.983 & 0.944 & 0.983 & 0.993 & 0.994 & 0.986 \\
\hline & 0.960 & 0.980 & 0.978 & 0.953 & 0.981 & 0.993 & 0.996 & 0.991 \\
\hline & 0.960 & 0.984 & 0.981 & 0.958 & 0.985 & 0.993 & 0.997 & 0.989 \\
\hline & 0.958 & 0.979 & 0.979 & 0.966 & 0.988 & 0.993 & 0.997 & 0.992 \\
\hline & 0.962 & 0.983 & 0.979 & 0.967 & 0.986 & 0.994 & 0.996 & 0.994 \\
\hline \multirow{8}{*}{$\begin{array}{l}\text { Prob. Drop to } \\
\text { unemployment } \\
\text { (period 1-8) }\end{array}$} & 0.017 & 0.015 & 0.019 & 0.084 & 0.005 & 0.005 & 0.003 & 0.011 \\
\hline & 0.024 & 0.012 & 0.016 & 0.018 & 0.007 & 0.005 & 0.001 & 0.005 \\
\hline & 0.010 & 0.017 & 0.016 & 0.020 & 0.004 & 0.005 & 0.002 & 0.003 \\
\hline & 0.011 & 0.017 & 0.018 & 0.017 & 0.008 & 0.005 & 0.003 & 0.001 \\
\hline & 0.015 & 0.013 & 0.016 & 0.017 & 0.005 & 0.005 & 0.001 & 0.006 \\
\hline & 0.019 & 0.019 & 0.019 & 0.015 & 0.004 & 0.006 & 0.002 & 0.002 \\
\hline & 0.012 & 0.013 & 0.018 & 0.015 & 0.006 & 0.003 & 0.003 & 0.001 \\
\hline & 0.000 & 0.000 & 0.000 & 0.000 & 0.000 & 0.000 & 0.000 & 0.000 \\
\hline \multirow{8}{*}{$\begin{array}{l}\text { Variance } \\
\text { log wage } \\
\text { (period 1-8) }\end{array}$} & 0.138 & 0.124 & 0.125 & 0.129 & 0.180 & 0.177 & 0.168 & 0.194 \\
\hline & 0.134 & 0.126 & 0.127 & 0.131 & 0.187 & 0.177 & 0.170 & 0.180 \\
\hline & 0.139 & 0.129 & 0.129 & 0.129 & 0.165 & 0.174 & 0.172 & 0.175 \\
\hline & 0.138 & 0.131 & 0.132 & 0.127 & 0.164 & 0.175 & 0.176 & 0.173 \\
\hline & 0.133 & 0.134 & 0.134 & 0.126 & 0.175 & 0.175 & 0.179 & 0.169 \\
\hline & 0.123 & 0.135 & 0.136 & 0.124 & 0.170 & 0.175 & 0.179 & 0.164 \\
\hline & 0.134 & 0.138 & 0.140 & 0.124 & 0.184 & 0.178 & 0.183 & 0.162 \\
\hline & 0.126 & 0.141 & 0.141 & 0.123 & 0.185 & 0.179 & 0.185 & 0.159 \\
\hline \multirow{7}{*}{$\begin{array}{l}\operatorname{cov}\left(y_{t}, y_{t}-1\right) \\
(\text { period } 2-8)\end{array}$} & 0.099 & 0.091 & 0.089 & 0.113 & 0.131 & 0.130 & 0.120 & 0.132 \\
\hline & 0.108 & 0.093 & 0.090 & 0.113 & 0.125 & 0.130 & 0.122 & 0.127 \\
\hline & 0.108 & 0.096 & 0.093 & 0.110 & 0.119 & 0.129 & 0.126 & 0.125 \\
\hline & 0.107 & 0.098 & 0.095 & 0.109 & 0.127 & 0.130 & 0.129 & 0.122 \\
\hline & 0.104 & 0.100 & 0.097 & 0.108 & 0.131 & 0.130 & 0.130 & 0.118 \\
\hline & 0.106 & 0.102 & 0.100 & 0.106 & 0.131 & 0.132 & 0.133 & 0.115 \\
\hline & 0.109 & 0.105 & 0.103 & 0.106 & 0.145 & 0.134 & 0.136 & 0.112 \\
\hline \multirow{7}{*}{$\begin{array}{l}\operatorname{cov}\left(M_{t}, M_{t}-1\right) \\
(\text { period 2-8) }\end{array}$} & 0.000 & 0.000 & 0.000 & 0.000 & 0.000 & 0.000 & 0.000 & 0.000 \\
\hline & 0.020 & 0.012 & 0.011 & -0.002 & 0.009 & 0.002 & 0.004 & 0.003 \\
\hline & 0.021 & 0.013 & 0.010 & 0.001 & 0.015 & 0.001 & 0.005 & -0.001 \\
\hline & 0.017 & 0.009 & 0.011 & 0.000 & 0.013 & 0.003 & 0.000 & -0.001 \\
\hline & 0.017 & 0.010 & 0.012 & $4 \overline{8} .001$ & 0.007 & 0.003 & 0.003 & 0.001 \\
\hline & 0.012 & 0.010 & 0.007 & 0.002 & 0.007 & 0.000 & 0.003 & 0.000 \\
\hline & 0.013 & 0.007 & 0.010 & 0.000 & 0.012 & 0.001 & 0.001 & -0.001 \\
\hline
\end{tabular}

